How Microaggressions Reinforce and Perpetuate Systemic Racism in the U.S.

\author{
Allison L. Skinner-Dorkenoo ${ }^{1 *}$ \\ Apoorva Sarmal $^{1 \wedge}$ \\ Chloe Andre ${ }^{\wedge}$ \\ Kasheena Rogbeer ${ }^{1}$ \\ ${ }^{1}$ Department of Psychology, University of Georgia, Athens, Georgia, US. \\ WORDS: 11,897
}

IN PRESS FOR PUBLICATION IN PERSPECTIVES ON PSYCHOLOGICAL SCIENCE

${ }^{\wedge}$ Shared second authorship, order was determined randomly

*Correspondence to: allison.skinner@uga.edu 


\begin{abstract}
The consequences of racial microaggressions are most often discussed at an interpersonal level. In this review, we contend that microaggressions play an important role in maintaining systems of racial oppression beyond the interpersonal context. Specifically, we illustrate how microaggressions establish White superiority in the U.S. by othering people of color (e.g., treating people of color as if they are not true citizens) and communicating that they are inferior (e.g., environmental exclusions and attacks, treating people of color as second-class citizens). We also present evidence that microaggressions play a role in protecting and reinforcing systemic racism. By obscuring systemic racism (e.g., false colorblindness, denial of individual racism) and promoting ideas that maintain existing systemic inequalities (e.g., the myth of meritocracy, reverse racism hostility), microaggressions provide cover and support for established systems of oppression. Overall, we find considerable evidence-from both empirical studies and real-world examples - that microaggressions contribute to the maintenance of systems of racial oppressions in the U.S. We conclude with a discussion of how we might begin to challenge this cycle by increasing awareness of systemic racism and the microaggressions that aid in its perpetuation.
\end{abstract}

KEYWORDS: microaggressions, racism, structural inequality, systemic racism 


\section{How Microaggressions Reinforce and Perpetuate Systemic Racism in the U.S.}

Microaggressions — subtle everyday slights committed against people of color ${ }^{1}$ as a result of their racial group membership — have gained increasing empirical attention over the last ten years (Williams et al., 2020). Historically, the study of microaggressions has centered around the experiences of people of color who face these slights and indignities (Sue, 2017; Sue et al., 2007). This focus on subjective experiences has been, and continues to be, critical in highlighting the factors that create a chilly climate for people of color in the U.S. and undermine the ability to create inclusive environments. However, the focus on subjective experiences has led some scholars to question the reality of microaggressions and the validity of the construct (Haidt, 2017; Lilienfeld, 2017)—although many of these critiques have been handily refuted (Sue, 2017; Williams, 2020a; Williams, 2020b). In this paper, we reinforce the gravity of this construct by considering how microaggressions contribute to the maintenance of a societal system in which White people are afforded greater status, power, and privilege than people of color (i.e. systemic racism). Although others have drawn a connection between microaggressions and systemic racism (e.g., Friedlaender, 2018; McTernan, 2018; Williams et al., 2020), our analysis highlights how microaggressions contribute to the establishment, reinforcement, and perpetuation of systemic racism within U.S. society. Thus, by connecting the enactment of microaggressions to systemic racism, we undermine the notion that microaggressions could ever be harmless and demonstrate that even in the absence of a victim, microaggressions cannot be overlooked.

\footnotetext{
${ }^{1}$ Microaggressions can also be based on membership in other marginalized groups (e.g., women). We define microaggressions in relation to race because our focus is on the role of race-related microaggressions in perpetuating systemic racism.
} 
In the pages that follow, we examine how the microaggressions identified by Williams and colleagues (2020) and Sue and colleagues (2007) can be seen as reinforcing and perpetuating systemic racism. We identify two core means through which microaggressions contribute to systemic racism: by (a) establishing White superiority and (b) protecting and defending the existing system of racial oppression. We contend that microaggressions establish White superiority by setting people of color apart from White people (e.g., by treating people of color as if they are not true citizens, tokenism) and then by communicating that people of color are inferior (e.g., environmental exclusions and attacks, treating people of color as second-class citizens). This system is then protected and defended by microaggressions that obscure systemic racism (e.g., false colorblindness, denial of individual racism) and promote ideas that maintain systemic inequalities (e.g., the myth of meritocracy, reverse racism hostility). Although it is clear that White people tend to be the perpetrators of racial microaggressions and the beneficiaries of systemic racial inequalities in the U.S., in perpetrating the microaggressions described here people of all races have the potential to reify systemic racism. The bulk of the research that we have identified and the systemic examples that we draw upon come from the U.S., thus our arguments are culturally bound and may not generalize to other societal contexts. Applicable findings from samples from outside the U.S. are identified as such and paired with information about the relevant cultural context.

\section{Establishing White Superiority}

We contend that microaggressions establish White superiority through a two-step process. First, there are microaggressions that set people of color apart as different from White people. These are messages that establish White people and culture as the norm or default and 
sideline or marginalize people of color. The second step in the sequence involves messages communicating that people of color are deficient or inferior to White people.

\section{Othering People of Color}

There are a number of microaggressions that can be seen as othering or communicating that White people and people of color are fundamentally different. As we detail below, racial categorization, connecting via stereotypes, exoticization and eroticization of people of color, assumptions about foreignness, and assumptions about intelligence can all be seen as contributing to a societal narrative and structure that normalizes Whiteness.

Racial Categorization, Tokenism, and Connecting Via Stereotypes. Williams et al. (2020) identified racial categorization as a microaggression in which people of color are compelled to disclose their racial or ethnic identity, which is often paired with the implied notion that people of a particular racial or ethnic group are all similar to one another. This microaggression signals to people of color that they are perceived to be different from White people (as this question is typically reserved for those who do not appear to be White); but it also signals to White people where racial lines are drawn. According to theories of racism and prejudice development (Bigler \& Liben, 2007; Roberts \& Rizzo, 2020), establishing the psychological salience of characteristics and categorizing people into groups are the first steps to establishing stereotypes and prejudices. The way these racial categorization questions are commonly asked (e.g., "What are you?" "Are you Black?") also has the tendency to underscore the notion that the racial category is fundamental to who the individual is (Beukeboom \& Burgers, 2019). In this way, race is established as a defining characteristic for understanding who people are, rather than a descriptive modifier (e.g., Black person). All of this evidence suggests that by categorizing people based on race and emphasizing race as a defining feature, 
the racial categorization microaggression lays the groundwork upon which systemic level biases can be constructed.

A related microaggression, which Williams (2020a) refers to as tokenism, involves asking people of color to speak for their racial or ethnic group (e.g., "Why do Asian people...?”). This microaggression has the potential to make people of color feel pigeonholed and stereotyped, but also signals a societal perception that members of a racial or ethnic group are all the same. In this way, tokenism not only communicates a message of difference between racial groups, but also implies homogeneity within groups of color.

Racial categorization (and the racial stereotyping that follows) can shape how people interact with one another, which Williams et al. (2020) refer to as connecting via stereotypes. When communicating with people of color, White people may sometimes try to modify their language and behavior to be consistent with their stereotypes of their conversational partner (e.g., changing one's greeting to a fist bump or "wassup" when interacting with a Black person). Although these linguistic and behavioral adjustments may be well-intentioned, they communicate to the target (and others who are present) that the person of color is different from White people, and therefore requires a different communication style.

Exoticization and Eroticization of People of Color. The tendency to stereotype people of color and their characteristics as "exotic" or sexually exciting, is called exoticization and eroticization (Williams et al., 2020). In U.S. culture, Latina/o/ $\mathrm{x}^{2}$ and Black people are often hypersexualized (McCabe, 2009; Anderson et al., 2018) and women of Asian descent tend to be sexually fetishized (Zheng, 2016). This tendency has been characterized as a microaggression

\footnotetext{
${ }^{2}$ Although "Hispanic" is currently the most popular pan-ethnic self-identifying label (Noe-Bustamante et al., 2020), this term more readily describes a linguistic identity (Spanish speaking), whereas Latina/o/x refers to a geographical location (Latin America). For this reason we felt that "Latina/o/x" better captures the racialized group we primarily reference in this review.
} 
because it can be experienced as objectification (treating someone as an object or body parts rather than a full human being) and also sets people of color apart as foreign and different from White people. At a systemic level, exoticization and eroticization of people of color reinforces the notion that people of color are fundamentally distinct from White people.

Language is a primary vehicle through which stereotypes (e.g., the Jezebel, the Latin lover) are established and reinforced (Beukeboom \& Burgers, 2019). For example, the tendency to use words such as "exotic" in reference to women of color communicates an association between race and sexuality. Applying such labels to whole groups of people (e.g., "Latinas are exotic") further implies that the sentiment is broadly applicable to members of the group rather than specific individuals. Thus, beyond communicating racial differences, we argue that sexualized stereotyping of people of color, which is perpetuated by microaggressions of this kind, may contribute to systemic racism in other distinct ways. As an example, eroticization may help explain why Black women are more likely to be sexually objectified than White women (Anderson et al., 2018).

Not a True Citizen. Treating people of color as if they are not true citizens of the U.S. (Sue et al., 2007, Williams et al., 2020) is a microaggression communicating that people of color do not really belong, making them feel excluded from society (Cheryan \& Monin, 2005). For instance, people of color are often asked about their origins, with the typical line of questioning going, "where are you from?," and when the person of color responds with a city or state in the U.S., they receive a follow-up question, "but where are you really from?" The implied message is that people of color are not true citizens of the U.S. (Ayala-López, 2020). At a broader societal level, this microaggression reinforces the notion that people of color are distinct from White people and, unlike White people, do not truly belong in the U.S. 
The tendency to think of U.S. citizens as White can be traced back to the origins of the U.S., with the Naturalization Act of 1790 explicitly limiting citizenship to White people. Yet, White children and adults in the U.S. continue to associate being "American" with being White in the present day (Brown, 2011; Devos \& Banaji, 2005; Zou \& Cheryan, 2017). Thus, when speakers communicate assumptions that people of color are foreign, it reinforces the notion that people of color are different from White people, and ultimately not true citizens (Zou \& Cheryan, 2017). Even complementary messages such as, "he speaks such good English," can communicate that members of a given group are not expected to speak English well or have a native U.S. accent (Ayala-López, 2020; Ruscher, 2017). Thus, statements of this kind have the potential to shape societal perceptions of who belongs and who is a true citizen.

History has illustrated that the systemic ramifications of perceiving people of color as foreign can be dramatic. In World War II, over 100,000 people of Japanese descent (most of whom were U.S. citizens) were removed from their homes and placed in concentration camps (Howard, 2009). Despite their U.S. nationality, people of Japanese descent were presumed to be a potential threat to the U.S. and therefore detained, at the expense of their personal rights and liberties as U.S. citizens. In contrast, German ${ }^{3}$ Americans-who were considered White-were allowed to proceed with their lives, uninterrupted. Experimental evidence from Yogeeswaran and Dasgupta (2010) suggests that such sentiments may still be present in contemporary U.S. society: The more strongly White people implicitly associated being "American" with being White, the less willing they were to select an Asian American job candidate for a national security position or endorse immigration policy proposed by an Asian American.

\footnotetext{
${ }^{3}$ It is also worth noting that more than 1,600 Nazi German scientists were recruited to immigrate to the U.S. for military projects following World War II (Proctor, 2000). Thus, even White people who were known to be enemies of the U.S. were treated more favorably than people of color.
} 
Assumptions that people of color in the U.S. are foreigners continue to have systemic impacts today, resulting in racial profiling (Epstein \& Goff, 2011; Fisher et al., 2011; Nier et al., 2012). Arizona SB 1070 requires police to assess the immigration status of anyone they reasonably believe may be an undocumented immigrant (Delgado, 2018) and makes it illegal for citizens to transport undocumented immigrants — which has resulted in the targeting of people of color (Bean \& Stone, 2012). Profiling of this kind is not limited to Arizona. In a random sample of 563 Latina/o/x residents of El Paso (TX), first, second, and third generation U.S. citizens all had a fairly high probability (.38-.59) of having been questioned by the police about their citizenship in the last five years (Morales et al., 2018). Thus, treating people of color like they are not true citizens of the U.S. establishes cognitive associations between U.S. citizenship and Whiteness, ultimately resulting in policies that systemically control and oppress people of color in the U.S. (e.g., Japanese concentration camps, Arizona SB 1070).

Ascription of Intelligence. The ascription of intelligence microaggression conveys the premise that intellectual ability is linked to race (Sue et al., 2007; Williams et al., 2020). Most notably, people of Asian descent are often assumed to be intelligent and educated, whereas Black people are assumed to be unintelligent and uneducated (Skinner et al., 2020a; Zou \& Cheryan, 2017). Whether positive (intelligent) or negative (unintelligent), ascriptions of intelligence can leave people of color feeling singled out and pigeonholed based on their race. This microaggression communicates that people of color are intellectually defined by their race, and as with the aforementioned microaggressions, reinforces the notion that they are fundamentally different from White people.

There are a variety of subtle ways in which ascriptions of intelligence can be transmitted through language, contributing to societal stereotypes based on race. Marked nouns, such as 
"Black honors student" (Ruscher, 2017), signal that something is non-normative: specifically, that Black students are not typically in the honors program. Regardless of whether the motivation is to reinforce the norm or to highlight student success, marked nouns perpetuate societal ideas of who is and is not ascribed intelligence, especially when they are not similarly used when referencing people of other races. Linguistic negations (e.g., he is not dumb vs. he is smart) can also reinforce ascriptions of intelligence by indicating that an individual is an exception to the perceived norm for their group (Beukeboom et al., 2010; Beukeboom et al., 2019). For example, a professor who remarks that a Black student is "not stupid," subtly conveys that this particular student is an exception to the societal stereotype that Black people are unintelligent. Similarly, stylistic modifications such as speaking slower or using shorter and simpler sentences when communicating with people of particular races transmits societal stereotypes about intelligence (Ruscher, 2017). Dupree and Fiske (2019) found robust evidence of a tendency among politically liberal White U.S. residents to "dumb" themselves down and speak less competently when communicating with Black people.

Ascriptions of intelligence can also be communicated via nonverbal signals. Children who observed a teacher display more positive, approving nonverbal signals toward one child (relative to another) tended to believe that the child who received positive nonverbal signals was smarter (Brey \& Shutts, 2018) and generalized these intelligence stereotypes to other children who belong to the same group (Brey \& Pauker, 2019). On the whole, evidence suggests that ascriptions of intelligence may be easily transmitted via subtle linguistic cues and nonverbal signals, even to children. Evidence of racial intelligence stereotyping among teachers (Chang \& Demyan, 2007) suggests that messages about racialized differences and abilities are likely being transmitted even in early educational settings. 
The "model minority" stereotype, which confers intelligence onto people of Asian descent (Cheryan \& Bodenhausen, 2011), also reinforces the notion that Asian Americans are foreign — by asserting that their success is a result of the hard driving work ethic inherent to Asian cultures ( $\mathrm{Wu}, 2015)$. In addition to this impact, some evidence suggests that the "model minority" stereotype might contribute to racial biases against U.S. residents of Asian descent. Among White U.S. college students, perceptions that Asian people are intelligent and possess other "model minority" traits (e.g., ambitious, hardworking) have the potential to be threatening (Maddux et al., 2008), such that being placed in competition with Asian American students results in more negative attitudes toward Asian Americans.

\section{Messages Communicating that People of Color are Inferior}

Beyond the normalization of Whiteness and marginalization of people of color, microaggressions can communicate that people of color and their distinct cultures are inferior or pathological. In this section, we describe how the following microaggressions contribute to the systemic devaluation of people of color: ascriptions of intelligence, environmental exclusions and attacks, avoidance of people of color and treating people of color as second-class, assumptions about criminality and dangerousness, and pathologizing of the cultures of people of color.

Ascription of Intelligence. As noted in the previous section, the microaggression of ascribing intelligence based on race creates the illusion that people of color are intrinsically different from White people. We return to ascriptions of intelligence again in this section because in some cases ascriptions of intelligence propagate the notion that people of color (especially Black people) are inferior to White people. Intelligence and race have long been woven together in the U.S. - going all the way back to the Transatlantic slave trade - to reinforce 
White supremacy, and justify the oppression of Black people (Kendi, 2017). Although the link between race and intelligence has repeatedly been discredited, the notion that White people are genetically, morally, and intellectually superior to Black people has persisted in the U.S. for hundreds of years, and continues to receive scientific attention (Winston, 2020a; Winston, 2020b). Scientific racism has contributed to systemic racism in a number of ways, including supporting the efforts of the Ku Klux Klan, rationalizing the need for racial segregation (Plessy v. Ferguson), and justifying racial discrimination (Winston, 2020a; Winston, 2020b). Even in contemporary U.S. society, people who hold more biological conceptions of race tend to view systemic racial disparities (e.g., in income and education) as more natural and inevitable (Williams \& Eberhardt, 2008). For example, priming samples of predominantly White and Asian participants with biological (vs. socially constructed) conceptions of race significantly reduces concern about racial inequities (Williams \& Eberhardt, 2008). Taken altogether, it is clear that when people convey racial ascriptions of intelligence to others, they contribute to the perpetuation of societal ideas that have long been used to justify a system of racial oppression.

The broader impacts of ascribing intelligence based on race are present in other domains as well. A content analysis of the comments made by journalists in Sports Illustrated about NFL quarterback prospects over a 10 year period (1998-2007) showed that the performance of Black quarterbacks tended to be attributed to their strong athleticism—as opposed to their intellectual abilities (Mercurio \& Filak, 2010). In contrast, the performance of White quarterbacks was often attributed to intellectual abilities (and less so to athleticism). In other words, societal stereotypes about intelligence seemed to shape the way in which sports reporters interpreted athletes' performance. Perhaps more consequentially, ascriptions of intelligence seem to influence healthcare providers. A study examining the attitudes and biases of physicians indicated that 
they tended to perceive Black patients as less intelligent, educated, rational, and compliant with treatment recommendations than White patients (van Ryn \& Burke, 2000). van Ryn and Burke (2000) argue that these stereotypical perceptions of Black patients are particularly concerning because physicians' attitudes and beliefs have been shown to predict treatment decisions, quality of care, and ultimately, health outcomes. As such, ascribing intelligence based on race not only reinforces the notion of racial inferiority, but may also contribute to systemic racial disparities observed in the U.S. healthcare system and other important domains.

\section{Environmental Exclusions and Environmental Attacks. Environmental} microaggressions emerge through structural components of a social environment that can communicate to members of marginalized groups that they do not belong or are not valued (Sue et al., 2007). These microaggressions present themselves as (a) exclusion or omission from the social or cultural environment and (b) attacks that either disparage people of color or celebrate proponents of racist ideas and policies (Williams et al., 2020).

Environmental Exclusions. Environmental exclusions communicate to people of color that they do not belong or that the contributions of people who share their racial or ethnic identity are not valued. At a broader societal level, environmental exclusions center the contributions and experiences of White people and devalue those of people of color. Many institutions, such as universities and government buildings, have prominent wall space dedicated to honoring individuals historically affiliated with the organization. However, given the White male-dominated history of the U.S., these displays are often primarily (if not entirely) made up of White individuals, specifically White men. Those who encounter such spaces get a powerful, though often implicit, message about who is welcomed and valued in that space. Although these cues may go unnoticed among White people (especially men), evidence suggests that these 
implicit cues can unconsciously increase their self-esteem and cognitive performance (Dijksterhuis, 2004; Jraidi \& Frasson, 2010)—perhaps because they reinforce feelings of belonging and superiority. Furthermore, a series of studies demonstrated that subliminal exposure to White faces increased White participants' (from the Netherlands and the U.S.) racial biases against Black people (Smith et al., 2008). Similar processes may be taking place in U.S. public schools - where more than $80 \%$ of teachers are White (Rich, 2015) — and are likely compounded by a tendency for White teachers to reinforce norms of Whiteness (Hyland, 2005). Being raised in an environment where the intellectual authority is almost always White can have important implications for whose perspectives children value, trust, and respect. Similarly, scientific conventions in which all of the invited speakers are White men (Else, 2019) have been argued to reinforce societal notions of White (male) intellectual superiority.

In other cases, people of color are deliberately excluded. Prior to the 1960s, it was common for U.S. textbooks to include explicitly racist messages and dehumanizing stereotypes of people of color (e.g., referring to Native Americans as "savages"), which taught children that White people are superior to people of other races (Foster, 1999). The tone shifted in response to the U.S. Civil Rights Movement, but cultural narratives have continued to center the experiences and accomplishments of White people, largely omitting people of color and issues that reflect poorly on White people (Foster, 1999; Kurtiş et al., 2009; Mukherjee et al., 2015). When people of color are included in textbooks and educational curricula, they are often confined to specific chapters or times of the year (e.g., Black History Month) rather than being integrated into the broader historical narrative (King \& Brown, 2014; Luther, 2009; Wallace \& Allen, 2008). For topics that cannot be glossed over entirely, such as the 18th and 19th century conflicts between Native Americans and White invaders or the institution of slavery, cultural narratives often 
present sanitized versions of these events - minimizing their impact and omitting the most egregious and problematic elements (Fryberg \& Eason, 2017; Salter \& Adams, 2016). For instance, a major textbook publisher in the U.S. was criticized in 2015 for describing enslaved Africans as "immigrant workers," and it was not until 2018 that the Texas state school board acquiesced to teaching that slavery was the primary motivation for the U.S. Civil War (Greenlee, 2019). The omission of people of color and their stories from the historical narrative has been argued to be particularly problematic because individuals are often unaware of the gaps in their historical knowledge (Fryberg \& Eason, 2017). Moreover, those who are less aware of historical injustices tend to be less aware of contemporary manifestations of systemic racism (Bonam et al., 2019; Nelson et al., 2013).

People of color have historically been excluded from media representation in the U.S. To this day, White people are overrepresented across the board in all forms of media in the U.S. (Roberts \& Rizzo, 2020). The exclusion that is perhaps most striking is the case of Native Americans, whose presence in the U.S population is 14 times greater than their representation in popular U.S. TV shows (Tukachinsky et al., 2015; US Census Bureau, 2011). People of color have also been erased from religious iconography. In the U.S., Jesus Christ has generally always been depicted as a White man-in spite of ample evidence that this does not accurately represent his appearance (Blum \& Harvey, 2012). Moreover, erasures of people of color have consequences. Young children who consume more White-centric media have been shown to harbor stronger pro-White biases (Rizzo et al., 2019, as cited by Roberts \& Rizzo, 2020). Among both White and Black Christians in the U.S. (children and adults), conceiving of God as a White man predicts a tendency to believe that White people (especially White men) are particularly well-suited for leadership (Roberts et al., 2020). Indeed, nearly three quarters of the 
leaders of multiracial church congregations in the U.S. are White (Dougherty \& Emerson, 2018). There is also evidence that these representations causally impact racial attitudes, such that priming White people with White religious images (e.g., White Jesus, White God, White angels) heightens anti-Black attitudes (Howard \& Sommers, 2019).

Environmental Attacks. When people of color are represented in media, they are often negatively portrayed (e.g., as criminals; Dixon \& Linz, 2000). In fact, evidence suggests that this kind of environmental attack may be increasing. Between the years 2003 and 2009, lowstatus Black characters increased three-fold on U.S. TV shows, whereas high-status Black characters decreased in frequency (Tukachinsky et al., 2015). Nonverbal racial biases have also been detected in popular U.S. TV shows (which are exported all over the world), such that White characters systematically display more negative nonverbal signals toward Black characters than they do toward other White characters (Weisbuch et al., 2009). Exposure to biases against people of color in the media have been demonstrated to reinforce racial biases; greater consumption of racially biased entertainment predicted more anti-Black attitudes and stronger associations between Black people and criminality (Dixon, 2008; Tukachinsky et al., 2015; Weisbuch et al., 2009). Another form of environmental attack occurs through the common use of linguistic metaphors that link the word "black" to negative and immoral things (e.g., "blackmail," "blacklist," "black sheep") in the English language. The prevalence of these metaphors in our everyday interactions reinforces negative cultural associations with Black people (Miller, 1999; Winifred Kagwa, 1976).

Environmental attacks can also be perpetrated through cultural practices and traditions (e.g., holidays and songs), names (e.g., commemorating racist people and slurs or offensive nicknames), and symbols (e.g., flags and statues). For example, Christopher Columbus is 
nationally recognized and celebrated every year on Columbus Day, in spite of the atrocities he perpetrated against Indigenous communities (Eason et al., 2021). It has been argued that normalizing these environmental symbols of oppression (e.g., Columbus day) subtly reinforces racist sentiments and implicitly promotes White supremacy (Yearwood, 2018). Additionally, evidence suggests that these impacts are not mere accidents; for instance, most of the schools with Confederate namesakes were given those names during the Civil Rights movement, following the Brown v. Board of Education ruling (Buffington, 2017). The fact that Confederacy-related iconography spiked during periods of resistance to racial equality shows that these names were adopted with the intent to reinforce notions of White supremacy (Southern Poverty Law Center, 2019). This is corroborated by research showing that support for the Confederate flag is more strongly linked to racial resentment than to local history (Strother et al., 2017). Much like school naming, most monuments and symbols honoring the Confederacy were erected well after the U.S. Civil War-often in response to racial progress (Buffington, 2017). Perhaps most concerningly, O’Connell (2020) found evidence that counties with a Confederacy glorifying monument tended to have higher Black-White racial disparities in poverty. These heightened racial disparities were present even in counties without a history of a large enslaved population - relations were actually strongest in these locations - suggesting that the monuments themselves reinforced biases that contribute to systemic racism.

The environmental exclusions and attacks reviewed in this section touch on some of the ways in which structural factors challenge people of color's sense of belonging and esteem. Moreover, the elevation of White people and their accomplishments, the omission of people of color from the cultural narrative, and the devaluation of people of color reflect and reinforce a system of racial oppression that perpetuates White supremacy in broader society. 


\section{Avoidance of People of Color and Treating Them as Second-Class Citizens.}

Williams et al. (2020) present avoidance of people of color — such as physically distancing from people of color or dodging conversations about race — as a microaggression. This microaggression can leave people of color feeling alienated and rejected, while also prescribing that people of color should be socially avoided. Much of this communication is nonverbal, transmitting powerful messages about who to associate with in society, even in early childhood. As an example, 1-year-olds who observed their mother behave in a socially avoidant way toward a stranger (e.g., limited eye contact, stiff posture) subsequently exhibited more behavioral evidence of fear and more physical avoidance of that stranger. Prejudice against groups can even be acquired through exposure to biased nonverbal signals. Children and adults who observe one individual receive more negative nonverbal signals than another go on to disfavor the individual who receives more negative nonverbal signals, as well as others in the same demographic group (Skinner et al., 2017; Skinner et al., 2020b; Skinner \& Perry, 2020). In fact, children may even trust the messages conveyed by nonverbal signals over their own observations (Brey \& Shutts, 2018).

The second-class citizen microaggression refers to situations in which people of color are overlooked, or White people are given preferential treatment (Sue et al., 2007; Williams et al., 2020). Overlooking the thoughts, feelings, and experiences of people of color has clear implications for their psychological well-being. Failing to acknowledge the presence and needs of people of color can also result in much more tangible outcomes, such as overcrowded schools and inaccessible polling places. Beyond the impact that being treated as second-class citizens has on people of color, we argue that this form of microaggression potentially sets up and reinforces the expectation that White people are entitled to priority over people of color (Dupree 
et al., 2020). This is critical because, starting in childhood, humans tend to favor the status quo - believing that the way things are is the way they should be (e.g., Roberts et al., 2018; Roberts et al., 2017a; Roberts et al., 2017b). Adults from a number of different countries have been found to show a similar preference (García-Sánchez et al., 2019; Kay et al., 2009), such that those living in more unequal societies tended to perceive economic inequality as more desirable (García-Sánchez et al., 2019). Moreover, Kay and colleagues (2009) found that when Canadian participants were told that a particular group was underrepresented in an organization, they evaluated members of that group (within the organization) more negatively, perceiving them as less likeable and competent. Therefore, beyond merely favoring the status quo, evidence suggests that adults actively seek to support and maintain it.

The reaction of the White majority to societal changes in the U.S. provides further support of their desire to maintain the racial status quo. Exposure to information regarding the shifting demographics of the U.S. population increases both perceptions of threat and racial biases within the majority White population (Craig et al., 2018a; Craig et al., 2018b). For example, White participants in the U.S. who were exposed to Census Bureau projections of the U.S. becoming a "majority minority" nation show significant increases in racial bias and a stronger preference for affiliating with White U.S. residents (Craig \& Richeson, 2014; Skinner \& Cheadle, 2016). Moreover, these reactions seemed to be driven by fear that White people will lose their first-class status in the U.S.; reassurance that "the predominately White mainstream culture will be maintained" reduced participants' reactance (Craig \& Richeson, 2017). Changes in the racial status quo of U.S. political leaders can be similarly threatening. A striking example comes from the election of President Obama: a reminder of the racial significance of his election 
led White U.S. residents to show increased anti-Black bias (Skinner \& Cheadle, 2016) and beliefs that White people are victims of discrimination (Wilkins \& Kaiser, 2014).

In our increasingly technological society, the prioritization of data obtained from White populations to train machine learning algorithms (Harwell, 2019) has led to the development of widely used tools that are not equipped to accurately assess people of color. For instance, a recent study found that among Black and White patients who were assigned the same level of health risk based on a commonly used scoring algorithm, Black patients were substantially sicker than White patients (Obermeyer et al., 2019). Given that this diagnostic tool has been used by U.S. healthcare providers to make decisions for more than 200 million patients each year, it has undoubtedly contributed to the perpetuation of race-based health disparities (Obermeyer et al., 2019). Recidivism risk assessment scores used in the criminal justice system are also influenced by algorithmic racial biases. An analysis of over 7,000 arrests in 2016 indicated that only $61 \%$ of those labeled high risk went on to reoffend in the next two years, but that Black defendants (relative to White defendants) were twice as likely to be mislabeled as high risk (Angwin et al., 2016). In 2016, these racially biased assessments were taken into consideration by judges from at least nine U.S. states when making sentencing decisions - illustrating the potential for tools of this kind to reify systemic racial biases in the criminal justice system (Angwin et al., 2016). Our final example is facial recognition software, which, as a result of inadequate training data, has been substantially better at accurately recognizing White faces than the faces of people of color (Grother et al., 2019). Inaccuracies in the identification of people of color have already led to wrongful arrests (Allyn, 2020), which are likely to persist if underlying biases in the software remain unaddressed. Taken together, we submit that avoiding people of color and treating them as second-class citizens sets up the societal assumption that White people are entitled to 
preferential treatment in the U.S., resulting in attitudes, policies, and algorithms that reinforce systemic racial inequality.

Criminal Assumptions. The criminal assumptions microaggression refers to the presumption that people of color are inherently criminal or dangerous. Black and Latina/o/x individuals in the U.S. routinely face this kind of microaggression as they tend to be stereotyped as criminal, aggressive, and violent (Sigelman \& Tuch, 1997; Skinner et al., 2020a; Zou \& Cheryan, 2017). Clearly there are direct negative impacts on people of color who face assumptions of criminality—such as being stopped and frisked (Hetey \& Eberhardt, 2014)—but this stereotype has impacts well beyond interpersonal contexts. Criminal assumptions can be subtly communicated through nonverbal behaviors, such as a woman clutching her purse when a Latina/o/x person enters an elevator or a man crossing the street to avoid encountering a Black person. Exposure to nonverbal microaggressions of this kind is consequential because it can heighten racial prejudices and perpetuate stereotypes (e.g., Castelli et al., 2012; Castelli et al., 2008; Weisbuch et al., 2009; Willard et al., 2015). For example, predominantly White participant samples from Italy and the U.S. who observed a White person display relatively negative (vs. positive) nonverbal signals toward a Black person subsequently demonstrated increased anti-Black bias (e.g., Castelli et al., 2012; Willard et al., 2015).

Implicit messages disseminated through interpersonal conversations and media also contribute to the propagation and reinforcement of criminal assumptions. U.S. residents tend to implicitly associate the presence of Black people in a geographical location (e.g., neighborhood) with danger, regardless of crime rates (Quillian \& Pager, 2001), which is often reinforced by how White people talk about different neighborhoods (DiAngelo, 2018). These biased perceptions may help explain why Black-owned homes and neighborhoods tend to be devalued 
in the U.S. (Bonam et al., 2016; 2017; 2020). Social media applications, such as "Nextdoor," also provide a platform for stereotypes about neighborhood safety and criminal activity to be circulated (Kurwa, 2019). Further, these websites and applications can create echo chambers that amplify an "us" versus "them" mentality that is conducive to stereotyping. By increasing racial panic under the guise of public safety, the White individuals in these neighborhoods not only make their Black neighbors feel unwelcome, but can actually result in an increased police presence—which already tends to be biased against people of color (Kurwa, 2019).

Outside of social media, traditional news outlets also reinforce criminal stereotypes by emphasizing Black criminal offenders (Bjornstrom et al., 2011)—often bringing up or implying criminal activity even when Black individuals are the victims (Dukes \& Gaither, 2017). The myth of the Black teen "super predator" that dominated the media and politics in the 1990s is one example that is thought to have been a major contributor to the dramatic increase in juvenile incarceration rates during that time (Miller et al., 2006). Although there has been a recent push to highlight racial disparities in the criminal justice system, these well-intentioned efforts can reinforce criminal stereotypes and increase support for punitive incarceration policies among White U.S. residents (Hetey \& Eberhardt, 2014; Hetey \& Eberhardt, 2018). Criminal associations may also impact judgments and behavior. For instance, participants in the U.S. who report a higher fear of crime tend to feel more threatened by Black people and be less likely to support police reform (Skinner \& Haas, 2016). White civilian participants and police officers (of various racial backgrounds) were quicker to identify crime-related objects (e.g., guns) when primed with Black faces (Eberhardt et al., 2004), and meta-analytic evidence indicates that participants in the U.S. tend to "shoot" armed Black targets faster than armed White targets in experimental simulations (Mekawi \& Bresin, 2015). In fact, sociologists and legal scholars have 
argued that the criminalization of Black men has led to racial disparities in policing and served to reinforce systemic racism (Alexander, 2020; Gilbert \& Ray, 2016).

These criminal assumptions can also have serious impacts outside of a law enforcement context. Stereotypical associations with criminal or violent behavior have been attributed to Black children as early as preschool. U.S. teachers who were told to keep an eye out for challenging behavior in the classroom spent significantly more time looking at Black children (especially boys) than White children (Gilliam et al., 2016). Other work has shown that given the same behavior (e.g., sleeping in class), samples of predominantly White female teachers were more likely to label Black students (vs. White students) as troublemakers-especially when the child had already committed a previous behavioral infraction (Okonofua \& Eberhardt, 2015). Teachers were also more likely to indicate that they could see themselves suspending the Black student in the future. This pattern of increased monitoring and heightened punitiveness in response to the misbehavior of Black children contributes to the "school-to-prison pipeline," in which disciplinary actions in schools lead directly and indirectly to incarceration (Heitzeg, 2009). For instance, zero tolerance policies and out of school suspensions can increase the amount of time children and adolescents spend unsupervised-increasing their likelihood of getting involved in criminal activity (Cuellar \& Markowitz, 2015; Wilson, 2014). Thus, assumptions of criminality not only increase the likelihood that the behavior of Black students will be seen as troublesome or criminal, but also have the potential to increase exposure to criminal activity.

Pathologizing the Culture and Appearance of People of Color. The pathologizing culture and appearance microaggression refers to messages that derogate the cultural values and practices of people of color. Within the U.S., this trend is characterized by favoring the cultural 
practices — such as music, beauty standards, and interaction styles — of White people over those of people of color. On an individual level, comments that pathologize cultural values (e.g., referring to Black hair textures as unprofessional or telling someone they are "pretty for a Black girl") can be hurtful and offensive. When White cultural values are set as the norm, people of color are compelled to alter themselves to attempt to fit within systems that simply were not designed with them in mind — which can have costs. In higher education, for example, facing cultural mismatches can negatively impact students' academic performance (Stephens et al., 2012). Moreover, pathologizing the culture and appearance of people of color sends a broader societal message that success is contingent upon assimilation into White cultural values and practices, and that any deviation from the norm is problematic (Marinari, 2005). In the paragraphs that follow, we discuss the myriad ways in which pathologizing the culture and appearance of people of color is not only self-perpetuating (spreading the message that White cultural norms are superior), but also leads to and exacerbates systemic racial inequalities in employment, education, and policy (among others).

Pathologizing the cultural values of people of color has had consequential impacts on the educational system. Many common cognitive assessment tests (e.g., IQ tests, SAT) are culturally specific, such that they rely upon knowledge of White U.S. culture (Boykin, 1977; Sue, 2017; Johnston, 2010). Consequently, White people in the U.S. tend to perform better on mainstream cognitive assessments (designed to tap into their cultural knowledge), whereas Black Americans have been shown to perform better on tests that are based on Black American cultural knowledge (Boykin, 1977; Franklin \& Fulani, 1974; Williams, 1972). These cognitive assessments — which have been established to have ethnic and socio-economic biases — can impact access to opportunities and resources such as college admissions or scholarship funding 
(Kidder \& Rosner, 2002), creating a barrier for people of color that reinforces systemic inequalities.

The speaking styles and accents of people of color are also pathologized. Although African American English (AAE, also known as African American Vernacular English) was derived from the style of English spoken by early British invaders in the U.S. (Poplack, 2009), AAE is now societally stigmatized because it deviates from the style of English currently spoken by White people (Baugh, 2000; Craft et al., 2020; Williams, 1997). U.S. residents also tend to favor non-native accents emerging from predominantly White countries (e.g., France) versus countries that are predominately made up of people of color (e.g., Mexico). One study found that U.S. participants considered immigrants speaking with non-native accents to be speaking "broken" English, with the exception of Western Europeans (i.e., White Europeans)—whose accents were generally perceived to sound more "correct" (Lindemann, 2005). Participants described the accents of Western Europeans as "sexy," "sophisticated," and "romantic," whereas they characterized the accents of Mexican immigrants as "sloppy" and the accents of Chinese immigrants as "choppy" (Lindemann, 2005). These findings demonstrate that social perceptions in the U.S. are often tainted by an individual's ability to speak with a White linguistic style and accent, which can have wide ranging consequences. For example, testimony given in AAE is less likely to be accurately transcribed by court reporters - sometimes dramatically altering the meaning of a message and impacting whether it is considered during jury deliberations (Jones et al., 2019). In fact, misinterpretation of key witness testimony delivered in AAE (sometimes leading it to be completely disregarded) is believed to have been an important contributor to the outcomes of high profile cases (e.g., George Zimmerman's trial for the killing of Trayvon Martin; Rickford \& King, 2016). Moreover, regardless of language proficiency, those who 
speak with non-dominant accents often face discrimination in housing, employment, and in legal contexts (Gluszek \& Dovidio, 2010).

The musical and artistic traditions that are culturally valued and incorporated into U.S. public education also generally reflect an emphasis on musical and artistic styles practiced by White people (Acuff, 2018; Roy \& Dowd, 2010). For instance, the bulk of music education in the U.S. is centered on White composers, musicians, and styles of music (e.g., European classical music), often with only passing mention of the styles of music popularized by people of color in the U.S. and around the world (e.g., hip-hop, Bollywood, Afropop)—reinforcing a notion of White cultural supremacy (Bradley, 2007). This narrow approach to musical education is particularly striking given that nearly every style of music originating from the U.S. can be traced back to Black artists (Morris, 2019).

Holidays and the standard work week in the U.S. are organized around Christian religious and cultural traditions_- businesses are often closed on Sundays (the day Christian religious services are held), Christmas, and Easter. As a result, those who belong to a faith other than Christianity may often find themselves in situations where they have to choose between their professional and cultural values in ways that those for whom the system was built-White Christians - do not. One of the most striking examples of pathologizing the cultural traditions of people of color comes from the Muslim community in the U.S., among whom basic religious practices (such as prayer) may draw attention and ultimately put them in danger (Livengood \& Stodolska, 2004). An NYPD report released after the 9/11 terrorist attacks advocated for police profiling based on appearance (e.g., traditional Islamic attire, wearing a beard) and cultural practices, such as prayer (Aziz, 2012). Beauty and professionalism standards in the U.S. are also dictated by White norms. Historically, it was not uncommon for employers to explicitly ban 
hairstyles and dress that are worn by people of color, such as Black natural hairstyles and hijabs (Greene, 2013). Although certain types of hairstyles may no longer be explicitly banned in contemporary society, Black female job candidates who wear natural hairstyles continue to be perceived as less professional and less likely to succeed in Corporate America (Opie \& Phillips, 2015).

Black spaces (e.g., schools, communities) in the U.S. are also pathologized-such that they are routinely characterized as unsafe, rundown, resource-lacking, dangerous, and overpopulated, whereas White spaces tend to be described as safe, wealthy, well-maintained, and clean (Bonam et al., 2016). In fact, White prospective home buyers expect that a home will be worth substantially less when it is Black-owned (Bonam et al., 2016), potentially contributing to systemic racial wealth disparities. A 2018 analysis indicated that homes in Black neighborhoods are undervalued by an average of $\$ 48,000$ per home (Perry et al., 2018). These characterizations also seem to impact auto insurance premiums, such that after statistically accounting for risk (based on auto insurance claims), premiums are higher in neighborhoods with more people of color than they are in predominantly White neighborhoods (Angwin et al., 2017). Systemic devaluation has also plagued schools that predominantly serve students of color, contributing to stereotypes that schools in Black neighborhoods are poor quality and do not provide adequate education (Bonam et al., 2016). The tendency to devalue Black educational institutions also extends to colleges and universities, such that White people in the U.S. perceive historically Black colleges and universities to be of lower quality, less rigorous, and less prestigious than predominantly White serving institutions (Boykin, 2018). The devaluation of products and spaces associated with Black people in the U.S. (i.e., pathologizing Black culture) has been 
argued to be part of a dynamic that not only reinforces racial stereotypes, but also perpetuates systemic racial inequality (Bonam et al., 2017).

This elevation of Whiteness is also apparent in recent immigration policy discussions. In 2018, U.S. President Donald Trump insisted that rather than accepting immigrants from, as he referred to them, "shithole countries" (which were all countries predominantly made up of people of color), the U.S. should focus on bringing in immigrants from "countries like Norway" (i.e., White European countries; Dawsey, 2018). When the White House was asked to justify this statement, a spokesperson said that U.S. immigration policy should focus on those who can more easily assimilate into U.S. (i.e., White) culture (Dawsey, 2018).

Our review of how the norms, cultures, products, and spaces of people of color are devalued in the U.S. is only the tip of the iceberg. The numerous ways in which White cultural supremacy is implicitly and explicitly demonstrated (and reinforces systemic racism) in the U.S. cannot be adequately captured in a few pages. As stated by Roberts and Rizzo (2020, p. 18), "American society teaches American citizens that Whiteness is superior," and failure to challenge that narrative leads to the internalization of White cultural supremacy by children and adults who are socialized in U.S. society. The elevation of White culture over all others has far reaching impacts, reinforcing and perpetuating existing racial disparities in the U.S.

\section{Protecting and Maintaining Systemic Racism}

Thus far we have focused on the role microaggressions play in transmitting racist attitudes and reinforcing systemic racism. In this section, we discuss the role of microaggressions in protecting White superiority and maintaining systemic racism. By obscuring and deflecting attention from systemic racism, the microaggressions we discuss below provide cover and support for established systems of oppression. Specifically, we review 
evidence that denial of individual racism, false colorblindness, ascriptions of intelligence, the myth of meritocracy, and reverse racism hostility all play a role in protecting and reinforcing systemic racial inequality.

\section{Denial of Individual Racism}

Denial of individual racism describes the refusal to take responsibility for one's own racially biased behavior (Sue et al., 2007; Williams et al., 2020). Often this denial of responsibility involves morally credentialing oneself through social identities (e.g. as a member of a societally devalued group), associations (e.g., friends, family members, co-workers), or experiences (e.g., having voted for a person of color, taught at an inner-city school). At an interpersonal level, messages of this kind invalidate the experiences of people of color by insinuating that their feelings are unfounded given that the perpetrator has moral credentials to prove that they are not racist.

These microaggressions not only excuse racist ideas and actions at an individual level, but also have the potential to reinforce systemic disparities. For instance, Thai et al. (2016) found that people who made racist comments about Asian people, but credentialed themselves by reporting (or demonstrating) that they had Asian friends, were perceived to be less racist. Perhaps more importantly, both White and Asian U.S. participants indicated that racist comments were more acceptable and harmless when they were made by a White individual who provided evidence of having Asian friends. Moreover, explicitly denying individual racism, even without moral credentials, leads individuals who display racial biases in hiring decisions to be perceived as less prejudiced and more of a good person (Perry et al., 2019b). Participants also reported greater willingness to associate with the person who displayed discriminatory behavior but denied bias (vs. admitting to having biases and intending to work on them). Credentialing 
oneself as a means of refuting accusations of racial bias has actually been established in federal employment discrimination law under the "same actor doctrine" (Quintanilla \& Kaiser, 2016). According to this doctrine, employers can shield themselves from employment discrimination claims from any employees that they hired because the fact that they hired the individual in the first place is interpreted as evidence against individual racism. Thus, this formalized bureaucratic denial of individual racism can be (and has been) used to uphold systemic racism in the workplace. Corporate diversity training has come to serve a similar purpose at an institutional level, such that organizations that implement diversity training are presumed to be non-prejudiced-making institutional racism more difficult to identify and successfully litigate (Dover et al., 2019). Taken together, the evidence suggests that denying individual racism grants greater latitude for individuals and organizations to behave in racially biased ways.

Furthermore, there is evidence that people who morally credential themselves tend to increase their discriminatory behavior. In a series of studies, predominantly White U.S. participant samples were presented with a hiring task in which one applicant had much stronger credentials than the others (Monin \& Miller, 2001). When the exceptionally strong candidate was Black (vs. White), and thus the candidate that was most often selected, participants were less likely to favor a Black candidate on a subsequent hiring task. In other words, once participants had demonstrated themselves to be unbiased — by selecting an exceptional Black candidatethey were more likely to disfavor Black candidates. In fact, merely reporting a positive interaction with a Black or Latina/o/x person has been shown to increase White participants' preferences for White applicants and elevate their tolerance for racial prejudice (Bradley-Geist et al., 2010). Similar patterns have been observed after the endorsement of a Black political candidate (Effron et al., 2009). U.S. citizens who were presented with the option to indicate 
whether they would vote for Barack Obama — and indicated that they would — were more likely to favor a White applicant on a subsequent hiring task. After indicating that they would vote for Barack Obama, participants who were relatively high in modern racism (e.g., agreeing that Black people "are getting too demanding in their push for equal rights") also tended to recommend that less money be allocated to a charitable organization serving a low-income Black American community (Effron et al., 2009).

\section{False Colorblindness}

Previously referred to by Sue et al. (2007) as “colorblindness," Williams et al. (2020) renamed this microaggression "false colorblindness" to capture the notion of colorblindness that is not truly genuine and is instead being used to maintain racial ignorance. Colorblind comments such as "I don't see race" seem to suggest that racial categories have no influence on an individual's behavior, emotions, or decision-making, such that they cannot possibly be racist (Perry et al., 2019a). For people of color, false colorblindness invalidates their lived experiences by dismissing the ways in which race has shaped the experiences and opportunities available to them (Neville al., 2000; Sue et al., 2007; Williams et al., 2020).

Looking beyond the interpersonal outcomes of colorblindness, we examine how racial colorblindness might reinforce and contribute to systemic racism in the U.S. Bonilla-Silva (2002) maintains that racial colorblindness has emerged as a rhetorical tool to avoid the appearance of racial bias, or perhaps even conceal racial conflict or injustice. In a series of recent studies, Karmali et al. (2019) showed how colorblindness is used by White people as a strategy to conceal bias when interpreting and describing ambiguous interracial interactions. Predominantly White samples of Canadian participants who viewed ambiguous images of a White person and a Black person interacting sometimes mentioned conflict in their descriptions 
$(50 \%)$, less often mentioned race in their descriptions (22\%)—but rarely mentioned both (11\% of participants). Tellingly, when participants were explicitly instructed to use racial labels in their descriptions, they became much less likely (62\% decrease) to mention conflict in their description of the scene. These findings provide evidence that colorblindness is strategically used to conceal or avoid acknowledging perceived racial conflict. This type of denial of conflict (and injustice) is reflected in the creation of colorblind movements (e.g., All Lives Matter) in response to efforts (i.e., Black Lives Matter) to raise awareness about systemic racial injustice in the U.S. (Burke, 2017).

Others have asserted that endorsing colorblind ideology allows White people to reinforce systems of racial oppression while still perceiving themselves as egalitarian (Plaut et al., 2018). The epistemologies of ignorance framework (Mills, 2007) goes even further, positing that colorblindness is used strategically to maintain ignorance about racial privilege, discrimination, and inequality (Mueller, 2017; Salter et al., 2018). Chow and Knowles (2016) found that when White people in the U.S. were exposed to information about White privilege, those who reported greater passive resistance to equality were more likely to support colorblind policies (e.g., barring the classification of U.S. residents by race and avoiding discussions of race in political debates). In this case, endorsement of colorblind policies seems to reflect a systematic effort to not only maintain personal ignorance, but also facilitate cultural ignorance by hindering the collection and discussion of racial information that could help remedy structural inequality.

Even merely being exposed to the norm of racial colorblindness can make discrimination more difficult to recognize and increase the likelihood that people will overlook injustices (Plaut et al., 2018). White and Asian U.S. children who were primed with colorblind ideology (e.g., "race is not important" and "we are all the same") were significantly less likely to identify both 
ambiguous and explicit racial discrimination against a Black student (Apfelbaum et al., 2010). Moreover, following exposure to colorblind messages, children's descriptions of discriminatory behavior were significantly less clear, and were ultimately less likely to elicit teacher intervention. Priming White U.S. residents with racial colorblindness can also increase their racial biases (Richeson \& Nussbaum, 2004). In sum, exposure to colorblind messages not only promotes a lack of awareness of systemic racial biases but may actually increase racial biases among White people in the U.S.

It is critical to note that colorblindness can also directly aid in perpetuating systemic racism. Consider the U.S. Army's ban on hair styles such as twists and cornrows (Cooper, 2014). From a colorblind perspective, there is nothing discriminatory about this policy, as it applies to everyone. Yet, the racial biases in this policy become apparent when one considers that these hairstyles are almost exclusively worn by Black people with afro-textured hair. Colorblind messages can also help garner public support for racist policies and agendas (HaneyLopez, 2014; Mendelberg, 2001). For instance, if a U.S. presidential candidate ran on a platform of preferential treatment for White citizens, the public would generally reject that. However, when racially biased messages are merely insinuated — using ostensibly race neutral language (e.g., referencing "thugs" or the "inner city") — they are much more likely to be supported. White U.S. residents who were exposed to arguments against social welfare programs that used explicit racial appeals (e.g., referencing the use of welfare among lazy, uneducated Black people) showed no change in their attitudes toward social welfare programs (Wetts \& Willer, 2019). In contrast, an implicit racial appeal (e.g., referencing the use of welfare among people in the "inner city") significantly reduced support for such programs. 
At a societal level, there are a variety of domains in which race neutral (i.e., colorblind) justifications have historically been used to legally conceal and perpetuate structural racism in the U.S. One example of this is how school districts responded following the Brown v. Board of Education U.S. Supreme Court ruling. School boards in Arkansas and Mississippi asserted that students would now be assigned to schools based on their abilities and "fit" (Anderson, 2016) which allowed them to maintain racial segregation while ostensibly no longer using race to make school assignments. Another example of colorblindness allowing racism to continue unabated has to do with jury service. Batson v. Kentucky (1986) ruled that potential jurors could not be eliminated based on race, superficially putting an end to the practice of using all White juries. In reality, however, all people of color can be struck from the jury pool so long as race-neutral justification is provided (Alexander, 2020; Raphael \& Ungvarsky, 1993; Sommers \& Norton, 2007).

The system reinforcing effects of colorblind policies in the U.S. criminal justice system go well beyond the courtroom. The "War on Drugs" capitalized on existing criminal stereotypes of Black people to garner public support for so-called "tough on crime" policies that criminalized the behaviors of Black people. Crack cocaine, an alternative form of powder cocaine, was much more commonly used by Black people, whereas powder cocaine was preferred among White people (Alexander, 2020). Although these two substances are nearly identical (and equally harmful), laws were passed making penalties for crack 100 times greater, resulting in exponentially higher consequences for drug possession among Black people (Davis, 2011). More than 30 years later, the drug war has been credited with dramatically increasing the size of the prison population in the U.S.- by more than 1.7 million people (Alexander, 2020). 
Race neutral (i.e., colorblind) narratives also seem to allow systemic racism to masquerade as opposition to immigration (Bloch et al., 2020; Douglas et al., 2015). White U.S. citizens can openly express hostility toward "undocumented immigrants" and "illegal aliens," while maintaining that they are not racist (Douglas et al., 2015). Yet, it is clear who White U.S. citizens tend to think of as foreign—people of color (e.g., Brown, 2011; Devos \& Banaji, 2005). Thus, the implicit connotation when referencing "immigrants" and people who are "illegal" is that they are people of color. In fact, evidence suggests that colorblind racial attitudes are highly correlated with anti-immigrant sentiment (Hooghe \& Dassonneville, 2018). Both colorblindness and anti-immigrant sentiment were found to be strong predictors of voting for Donald Trump, who campaigned on a platform of hostility toward "illegal" immigrants in the 2016 U.S. Presidential Election (Hooghe \& Dassonneville, 2018). Relatedly, racial colorblindness has been postulated to aid policing policies (e.g., Arizona SB 1070) that appear race-neutral on the surface, but largely impact people of Latina/o/x descent (Delgado, 2018).

\section{Ascriptions of Intelligence-The "Model Minority" Stereotype}

The "model minority" stereotype, which we initially introduced as a microaggression that sets Asian people apart from people of other races, is rumored to have been constructed to maintain the racial order of White supremacy in the U.S. In 1965, the U.S. opened up to immigration from Asia, but it was largely restricted to well-educated professionals, such as physicians and engineers (Cheryan \& Bodenhausen, 2011). Thus, the Asian population in the U.S. tended to be high achieving and well-educated. The success of Asian Americans went on to serve as evidence that people of all races have the potential to be successful in the U.S. (if they apply themselves and work hard enough) — detracting attention from systemic racial oppression 
(Wu, 2015). Consequently, relatively wealthy, well-educated East Asian Americans were established as the benchmark against which the successes (and "failures") of other groups of color could be measured. Importantly, the "model minority" stereotype (that ascribes innate intelligence to Asian people) not only minimizes the challenges faced by other people of color (e.g., Black people), but also obscures discrimination and exacerbates disparities among Asian ethnic groups in the U.S. (Cheryan \& Bodenhausen, 2011; Kim, 1973; Wing, 2007).

\section{The Myth of Meritocracy}

The myth of meritocracy, which is common in the U.S. and in Western Europe, rests on the belief that anyone who works hard enough can be successful (Isaacs et al., 2008). This belief is referred to as a myth because it fails to acknowledge long standing systems of oppression that are present in these societies. As such, endorsement of the myth of meritocracy (e.g., asserting that White privilege does not exist) is invalidating to people of color by denying the existence of systemic racism and the impact it has had on the lives of people of color (Sue et al., 2007; Williams et al., 2020). Indeed, those who are most privileged in U.S. society tend to believe most strongly in the myth of meritocracy (Reynolds \& Xian, 2014), and greater belief in meritocracy is associated with reduced acknowledgement of White privilege (Knowles \& Lowery, 2012). Thus, meritocratic beliefs serve as justification for existing societal stratification.

Not only do meritocratic beliefs provide justification for the current system, exposure to the myth of meritocracy has the potential to exacerbate disparities. Sociological scholars have argued that the meritocratic principles (i.e., protestant work ethic) central to the beliefs of White U.S. evangelicals promote attitudes and policy positions that reinforce systemic racial inequalities (Emerson et al., 1999). Moreover, experimental evidence indicates that priming 
meritocracy increases the extent to which other people are blamed for their own misfortunes (Levy et al., 2006). With regard to self-evaluations, priming meritocracy increases the tendency to blame one's self for unfavorable outcomes among low status individuals, whereas for high status individuals it increases the tendency to believe unfavorable outcomes are the result of discrimination (McCoy \& Major, 2007). Meritocracy messages can also influence performance; priming French school children with meritocracy actually widened the achievement gap between students of different economic backgrounds (Darnon et al., 2018).

Promoting meritocracy also seems to impact the decisions of people in power. For instance, priming meritocracy reduced the amount of money participants were willing to donate to homeless people (Levy et al., 2006). In another study, participants who were told that an organization was meritocratic were more likely to "hire" members of groups that were overrepresented in the organization than members of groups that were underrepresented-in spite of their objectively equal qualifications (Castilla \& Benard, 2010). Learning that an organization was meritocratic also led participants to recommend that members of underrepresented groups receive less compensation. A systematic review of this literature concluded that priming meritocracy not only increases internal attributions for life outcomes (e.g., those who are successful earned it), but also increases prejudice, stereotyping, and discrimination against low-status groups (Madeira et al., 2019).

Consistent with the psychological evidence, legal scholars have argued that the pervasive myth of meritocracy in the U.S. leads people to overemphasize individual characteristics and obscure systemic patterns of discrimination. As an example, subjective evaluations (e.g., hireability ratings based on an interview) are interpreted as objective, such that people of color who receive lower hireability ratings after an interview are deemed to be objectively less 
qualified for the job (Lawton, 2000). Similar criticisms have also been made about faculty hiring committees at universities and the notion of candidate "fit" (White-Lewis, 2020). Meritocratic beliefs are also thought to reduce support for policies (e.g. affirmative action) designed to challenge systemic discrimination because such policies are perceived to taint the selection process, such that it is no longer based solely on "merit" (Knowles et al., 2014; Lawton, 2000).

\section{Reverse Racism Hostility}

Reverse racism hostility is characterized by envious and hostile reactions to people of color who are perceived as receiving benefits because of their race (Williams et al., 2020). Beyond the negative psychological impacts that hostile responses of this kind have on people of color, they also promote the societal notion that the accomplishments and successes of people of color are undeserved. The false notion that people of color must have received "free handouts" to get where they are (Bonilla-Silva et al., 2004) perpetuates the idea that people of color are inferior to White people. In educational contexts, the mere presence of students of color may be challenged by White students who claim that students of color could not have made it into these settings on their own merit (Lewis et al., 2000). Consider the 2012 U.S. Supreme Court case Fisher v. University of Texas at Austin. The plaintiff Abigail Fisher, a White woman, claimed that affirmative action policies ${ }^{4}$ obstructed her admission to the University of Texas, but a close examination of the university's admissions records revealed that 42 of the 47 students who were admitted with lower admissions scores than Ms. Fisher were White (Davis, 2014). Although White students represented $89 \%$ of those with lower scores than Ms. Fisher who were admitted, she argued that one of the five students of color who were admitted with lower scores stole her

\footnotetext{
${ }^{4}$ White women have benefited considerably more from Affirmative Action policies than people of color (Wise, 1998).
} 
rightful spot ${ }^{5}$. Thus, it appears that Ms. Fisher's case hinged upon the notion that White people are entitled to college admission over students of color.

\section{Discussion}

Despite the fact that the study of racial microaggressions has largely focused on their impact on people of color at an interpersonal level, the evidence we have presented here demonstrates that microaggressions also serve to reinforce structural racism. Specifically, we show that microaggressions do not just communicate messages to people of color, they subtly communicate messages to everyone in society about where group boundaries are drawn and which groups are most valued. When people of color are asked to racially identify themselves or treated as exotic fantasies - the underlying message is the same: people of color are different from White people and undeserving of equal treatment. A naive observer of U.S. society would quickly learn that some people are never asked "what are you?" or "where are you really from?" Still, other microaggressions communicate a societal message about the value of various groups. Members of U.S. society implicitly learn whose histories, culture, and contributions matter (and whose do not) through environmental exclusions. They also learn who deserves respect and trust (and who does not) through the conveyance of criminal assumptions, and whose language and culture is admirable and worthy of emulating through messages that pathologize the cultural values of people of color. Together, these microaggressions present a strong (though often implicit) societal message about the importance of race and the value of Whiteness - to all members of society.

\footnotetext{
${ }^{5}$ It is equally important to note that there were 168 Black and "Hispanic" students who had equivalent or higher admission scores than Ms. Fisher who were denied admission that year (2008).
} 
Yet, microaggressions contribute to systemic racism beyond simply establishing White superiority. Some microaggressions serve the purpose of reinforcing systemic racism, deflecting potential challenges, and obscuring the system of racial oppression altogether. For instance, messages that deny individual racism or promote false colorblindness lower defenses against racial bias and make both individual and systemic racism more difficult to identify. The myth of meritocracy communicates the idea that those who work the hardest and are most deserving will succeed, ergo the lack of people of color in high status positions can only be explained by their lack of merit. In other words, promoting the myth of meritocracy allows people to believe that there is no systemic racism—-people of color just haven't earned the privileges White people have. Thus, when these microaggressions are prevalent in a society, it leads members of that society to be less aware and more tolerant of racism.

\section{Challenging Microaggressions and Systemic Racism}

Given the myriad of subtle ways in which microaggressions can transmit biases and reinforce systemic racism, we next turn to the question of where we can go from here. Although remediating biases is not our primary purpose here, we believe that there is at least one promising avenue worth highlighting. Specifically, educating children and adults about the historical events that led to contemporary structural inequalities has been shown to increase their awareness of systemic racism (Bonam et al., 2019) and reduce their racial biases and stereotypes (Hughes et al., 2007). The Marley hypothesis posits that a lack of awareness about historical racism prevents people from recognizing contemporary systemic racism (Nelson et al., 2013). Thus, we posit that improving historical understanding through more accurate and well-balanced 
historical education could play an important role in increasing awareness of systemic racism and the microaggressions that aid in its perpetuation.

Historical education could also be used in a targeted way to take on specific types of microaggressions. For instance, increasing knowledge of the history of racially discriminatory citizenship laws in the U.S., such as the fact that it was not until 1924 that Native Americansthe original inhabitants of the land that is now the U.S.- - were granted U.S. citizenship rights, could help shift stereotypes about foreignness and second-class citizenship. Educating people about the construction of Black criminal stereotypes in the U.S.- - which were used to justify lynchings (Barnard, 1993) — may shift criminal assumptions. Likewise, educating people about legal forms of structural racial oppression (such as redlining), which can clearly be tied to current wealth and homeownership, could reduce meritocracy beliefs. The reproduction of ignorance and biased cultural narratives has been argued to be a critical means through which structural inequalities are maintained and perpetuated across generations (Salter et al., 2018). We submit that structural changes to the education system, that challenge these biased cultural narratives and rework the way we talk about and teach history are two important avenues through which we might tackle microaggressions (and the systemic racism that underlies and is reinforced by these microaggressions). However, much broader systemic changes are undoubtedly needed to fully eradicate systemic racism.

\section{Conclusion}

In this paper, we took on the question of how racial microaggressions might serve to perpetuate and reinforce systemic racism. Although the topic of microaggressions is typically discussed at an interpersonal level, we contend that beyond the interpersonal context, 
microaggressions play an important role in maintaining a system of racial oppression. In other words, microaggressions do not just convey messages to people of color, they subtly transmit messages to everyone in society. Specifically, White superiority is implicitly communicated through microaggressions that set White people apart from people of color (e.g., racial categorization, tokenism) and others that demean and disregard people of color (e.g., environmental exclusions, treating people of color as second-class citizens). This system is then protected and defended by microaggressions that obscure systemic racism (e.g., false colorblindness, denial of individual racism) and promote ideas that maintain existing systemic inequalities (e.g., the myth of meritocracy, reverse racism hostility). 


\section{References}

Acuff, J. B. (2018). Smog in the air: Passive positions, deracialization, and erasure in arts education. In A. Kraehe, R. Gaztambide-Fernández, B. Carpenter II (Eds.) The Palgrave handbook of race and the arts in education (pp. 515-533). Palgrave Macmillan, Cham. https://doi.org/10.1007/978-3-319-65256-6_30

Alexander, M. (2020). The new Jim Crow: Mass incarceration in the age of colorblindness. The New Press.

Allyn, B. (2020, June 24). 'The computer got it wrong': How facial recognition led to false arrest of Black man. NPR. https://www.npr.org/2020/06/24/882683463/the-computer-got-itwrong-how-facial-recognition-led-to-a-false-arrest-in-michig

Anderson, C. (2016). White rage: The unspoken truth of our racial divide. Bloomsbury Publishing USA.

Anderson, J. R., Holland, E., Heldreth, C., \& Johnson, S. P. (2018). Revisiting the Jezebel stereotype: The impact of target race on sexual objectification. Psychology of Women Quarterly. https://doi.org/10.1177/0361684318791543

Angwin, J., Larson, J., Kirchner, L., \& Mattu, S. (2017, April 17). Minority neighbors pay higher car insurance premiums than White areas with the same risk. ProPublica. https://www.propublica.org/article/minority-neighborhoods-higher-car-insurancepremiums-white-areas-same-risk

Angwin, J., Larson, J., Mattu, S., \& Kirchner, L. (2016, May 23). Machine bias. ProPublica. https://www.propublica.org/article/machine-bias-risk-assessments-in-criminal-sentencing 
Apfelbaum, E. P., Pauker, K., Sommers, S. R., \& Ambady, N. (2010). In blind pursuit of racial equality? Psychological Science, 21(11), 1587-1592. https://doi.org/10.1177/0956797610384741

Ayala-López, S. (2020). Outing foreigners. In L. Freeman \& J. Schroer (Eds.), Microaggressions and philosophy (1st ed., pp. 146-162). New York: Routledge. https://doi.org/10.4324/9780429022470

Aziz, S. F. (2012). From the oppressed to the terrorist: Muslim-American women in the crosshairs of intersectionality. Hastings Race \& Poverty Law Journal, 9, 191-263.

Barnard, A. L. (1993). The application of critical race feminism to the anti-lynching movement: Black women's fight against race and gender ideology, 1892-1920. UCLA Women's Law Journal, 3(1), 1-38.

Batson v. Kentucky (1986) 476 US. 79 (1986).

Baugh, J. (2000). Beyond Ebonics: Linguistic pride and racial prejudice. Oxford University Press on Demand.

Bean, M. G., \& Stone, J. (2012). Another view from the ground: How laws like SB1070 and HB2281 erode the intergroup fabric of our community. Analyses of Social Issues and Public Policy, 12(1), 144-150. https://doi.org/10.1111/j.1530-2415.2011.01267.x

Beukeboom, C. J., \& Burgers, C. (2019). How stereotypes are shared through language: A review and introduction of the Social Categories and Stereotypes Communication (SCSC) framework. Review of Communication Research, 7(2019), 1-37. https://doi.org/10.12840/issn.2255-4165.017

Beukeboom, C. J., Burgers, C., Szabó, Z. P., Cvejic, S., Lönnqvist, J.-E. M., \& Welbers, K. (2019). The negation bias in stereotype maintenance: A replication in five languages. 
Journal of Language and Social Psychology, 39, 219-236.

https://doi.org/10.1177/0261927x19869759

Beukeboom, C. J., Finkenauer, C., \& Wigboldus, D. H. J. (2010). The negation bias: When negations signal stereotypic expectancies. Journal of Personality and Social Psychology, 99(6), 978-992. https://doi.org/10.1037/a0020861

Bigler, R. S., \& Liben, L. S. (2007). Developmental intergroup theory: Explaining and reducing children's social stereotyping and prejudice. Current Directions in Psychological Science, 16(3), 162-166. https://doi.org/10.1111/j.1467-8721.2007.00496.x

Bjornstrom, E. E. S., Kaufman, R. L., Peterson, R. D., \& Slater, M. D. (2011). Race and ethnic representations of lawbreakers and victims in crime news: A national study of television coverage. Social Problems, 57(2), 269-293. https://doi.org/10.1525/sp.2010.57.2.269

Bloch, K. R., Taylor, T., \& Martinez, K. (2020). Playing the race card: White injury, White victimhood and the paradox of colour-blind ideology in anti-immigrant discourse. Ethnic and Racial Studies, 43, 1130-1148. https://doi.org/10.1080/01419870.2019.1648844

Blum, E. J., \& Harvey, P. (2012). The color of Christ: The son of God and the saga of race in America. Chapel Hill, NC: The University of North Carolina Press.

Bonam, C. M., Bergsieker, H. B., \& Eberhardt, J. L. (2016). Polluting black space. Journal of Experimental Psychology: General, 145(11), 1561-1582. https://doi.org/10.1037/xge0000226

Bonam, C. M., Nair Das, V., Coleman, B. R., \& Salter, P. (2019). Ignoring history, denying racism: Mounting evidence for the Marley hypothesis and epistemologies of ignorance. Social Psychological and Personality Science, 10(2), 257-265. https://doi.org/10.1177/1948550617751583 
Bonam, C. M., Taylor, V. J., \& Yantis, C. (2017). Racialized physical space as cultural product. Social and Personality Psychology Compass, 11(9), e12340.

https://doi.org/10.111/spc3.12340

Bonam, C., Yantis, C., \& Taylor, V. J. (2020). Invisible middle-class Black space: Asymmetrical person and space stereotyping at the race-class nexus. Group Processes \& Intergroup Relations, 23(1), 24-47. https://doi.org/10.1177/1368430218784189

Bonilla-Silva, E. (2002). The linguistics of color blind racism: How to talk nasty about Blacks without sounding "racist." Critical Sociology, 28(2), 41-64. https://doi.org/10.1177/08969205020280010501

Bonilla-Silva, E., Lewis, A., \& Embrick, D. G. (2004). "I did not get that job because of a Black man...": The story lines and testimonies of color-blind racism. Sociological Forum, 19(4), 555-581. https://doi.org/10.1007/s11206-004-0696-3

Boykin, A. W. (1977). Experimental psychology from a black perspective: Issues and examples. Journal of Black Psychology, 3(2), 29-49. https://doi.org/10.1177/009579847700300209

Boykin, C. M. S. (2018). Negatively stereotyping historically Black colleges and universities as an intergroup process (Doctoral dissertation, UC Berkeley).

Bradley, D. (2007). The sounds of silence: Talking race in music education. Action, criticism, and theory for music education, 6(4), 132-162.

Bradley-Geist, J. C., King, E. B., Skorinko, J., Hebl, M. R., \& McKenna, C. (2010). Moral credentialing by association: The importance of choice and relationship closeness. Personality and Social Psychology Bulletin, 36(11), 1564-1575. https://doi.org/10.1177/0146167210385920 
Brey, E., \& Pauker, K. (2019). Teachers’ nonverbal behaviors influence children's stereotypic beliefs. Journal of Experimental Child Psychology, 188, 104671. https://doi.org/10.1016/j.jecp.2019.104671

Brey, E., \& Shutts, K. (2018). Children use nonverbal cues from an adult to evaluate peers. Journal of Cognition and Development, 19(2), 121-136. https://doi.org/10.1080/15248372.2018.1449749

Brown, C. S. (2011). American elementary school children's attitudes about immigrants, immigration, and being an American. Journal of Applied Developmental Psychology, 32(3), 109-117. https://doi.org/10.1016/j.appdev.2011.01.001

Brown v. Board of Education 347 U.S. 483 (1954), 494.

Buffington, M. L. (2017). Contemporary culture wars: Challenging the legacy of the confederacy. Journal of Cultural Research in Art Education, 34, 45-59.

Burke, M. A. (2017). Colorblind racism: Identities, ideologies, and shifting subjectivities. Sociological Perspectives, 60(5), 857-865. https://doi.org/10.1177/0731121417723827

Castelli, L., Carraro, L., Pavan, G., Murelli, E., \& Carraro, A. (2012). The power of the unsaid: The influence of nonverbal cues on implicit attitudes. Journal of Applied Social Psychology, 42(6), 1376-1393. https://doi.org/10.1111/j.1559-1816.2012.00903.x

Castelli, L., De Dea, C., \& Nesdale, D. (2008). Learning social attitudes: children's sensitivity to the nonverbal behaviors of adult models during interracial interactions. Personality \& Social Psychology Bulletin, 34(11), 1504-1513. https://doi.org/10.1177/0146167208322769

Castilla, E. J., \& Benard, S. (2010). The paradox of meritocracy in organizations. Administrative Science Quarterly, 55(4), 543-676. https://doi.org/10.2189/asqu.2010.55.4.543 
Chang, D. F., \& Demyan, A. L. (2007). Teachers' stereotypes of Asian, Black, and White students. School Psychology Quarterly, 22(2), 91-114. https://doi.org/10.1037/10453830.22 .2 .91

Cheryan, S., \& Bodenhausen, G. V. (2011). Model minority. In S. M. Caliendo \& C. D. McIlwain (Eds), Routledge Companion to Race \& Ethnicity (pp. 173-176). New York: Routledge.

Cheryan, S., \& Monin, B. (2005). "Where are you really from?”: Asian Americans and identity denial. Journal of Personality and Social Psychology, 89(5), 717-730. https://doi.org/10.1037/0022-3514.89.5.717

Chow, R. M., \& Knowles, E. D. (2016). Taking race off the table: Agenda setting and support for color-blind public policy. Personality and Social Psychology Bulletin, 42(1), 25-39. https://doi.org/10.1177/0146167215611637

Cooper, H. (2014, April 20). Army's ban on some popular hairstyles raises ire of Black female soldiers. The New York Times. https://www.nytimes.com/2014/04/21/us/politics/armysban-on-some-popular-hairstyles-raises-ire-of-black-female-soldiers.html

Craft, J. T., Wright, K. E., Weissler, R. E., \& Queen, R. (2020). Language and discrimination: Generating meaning, perceiving identities, and discriminating outcomes. Annual Review of Linguistics, 6(1), 389-407. https://doi.org/10.1146/annurev-linguistics-011718-011659

Craig, M. A., \& Richeson, J. A. (2014). More diverse yet less tolerant? How the increasingly diverse racial landscape affects white Americans' racial attitudes. Personality and Social Psychology Bulletin, 40(6), 750-761. https://doi.org/10.1177/0146167214524993 
Craig, M. A., \& Richeson, J. A. (2017). Information about the US racial demographic shift triggers concerns about anti-White discrimination among the prospective White “minority”. PloS one, 12(9), e0185389. https://doi.org/10.1371/journal.pone.0185389

Craig, M. A., Rucker, J. M., \& Richeson, J. A. (2018a). Racial and political dynamics of an approaching “majority-minority” United States. The ANNALS of the American Academy of Political and Social Science, 677(1), 204-214. https://doi.org/10.1177/0002716218766269

Craig, M. A., Rucker, J. M., \& Richeson, J. A. (2018b). The pitfalls and promise of increasing racial diversity: Threat, contact, and race relations in the 21st century. Current Directions in Psychological Science, 27(3), 188-193. https://doi.org/10.1177/0963721417727860

Cuellar, A. E., \& Markowitz, S. (2015). School suspension and the school-to-prison pipeline. International Review of Law and Economics, 43, 98-106. https://doi:10.1016/j.irle.2015.06.001

Darnon, C., Wiederkehr, V., Dompnier, B., \& Martinot, D. (2018). 'Where there is a will, there is a way': Belief in school meritocracy and the social-class achievement gap. British Journal of Social Psychology, 57(1), 250-262. https://doi.org/10.1111/bjso.12214

Dougherty, K. D., \& Emerson, M. O. (2018). The changing complexion of American congregations. Journal for the Scientific Study of Religion, 57(1), 24-38.

Davis, K. (2014). On the case. Diverse Issues in Higher Education, 30(26), 10-11.

Davis, L. (2011). Rock, powder, sentencing-making disparate impact evidence relevant in crack cocaine sentencing. The Journal of Gender, Race, \& Justice, 14, 375-404.

Dawsey, J. (2018, January 12). Trump derides protections for immigrants from 'shithole' countries. The Washington Post. https://washingtonpost.com/politics/trump-attacks- 
protections-for-immigrants-from-shithole-countries-in-oval-officemeeting/2018/01/11/bfc0725c-f711-11e7-91af-31ac729add94_story.html

Delgado, D. J. (2018). “My deputies arrest anyone who breaks the law”: Understanding how color-blind discourse and reasonable suspicion facilitate racist policing. Sociology of Race and Ethnicity, 4(4), 541-554. https://doi.org/10.1177/2332649218756135

Devos, T., \& Banaji, M. R. (2005). American = White $?$ Journal of Personality and Social Psychology, 88, 447-466. https://doi.org/10.1037/0022-3514.88.3.447

DiAngelo, R. J. (2018). White fragility: Why it's so hard for White people to talk about racism. Beacon Press.

Dijksterhuis, A. P. (2004). I like myself but I don't know why: Enhancing implicit self-esteem by subliminal evaluative conditioning. Journal of Personality and Social Psychology, 86(2), 345-355. https://doi.org/10.1037/0022-3514.86.2.345

Dixon, T. L. (2008). Network news and racial beliefs: Exploring the connection between national television news exposure and stereotypical perceptions of African Americans. Journal of Communication, 58(2), 321-337. https://doi.org/10.1111/j.1460-2466.2008.00387.x

Dixon, T. L., \& Linz, D. (2000). Overrepresentation and underrepresentation of African Americans and Latinos as lawbreakers on television news. Journal of Communication, 50(2), 131-154. https://doi.org/10.1111/j.1460-2466.2000.tb02845.x

Douglas, K. M., Sáenz, R., \& Murga, A. L. (2015). Immigration in the era of color-blind racism. American Behavioral Scientist, 59(11), 1429-1451. https://doi.org/10.1177/0002764214566502 
Dover, T. L., Kaiser, C. R., \& Major, B. (2019). Mixed Signals: The unintended effects of diversity initiatives. Social Issues and Policy Review, 14(1), 152-181. https://doi.org/10.1111/sipr.12059

Dukes, K. N., \& Gaither, S. E. (2017). Black racial stereotypes and victim blaming: Implications for media coverage and criminal proceedings in cases of police violence against racial and ethnic minorities. Journal of Social Issues, 73, 789-807. https://doi.org/10.1111/josi.12248

Dupree, C. H., \& Fiske, S. T. (2019). Self-presentation in interracial settings: The competence downshift by White liberals. Journal of Personality and Social Psychology, 117(3), 579604. https://doi.org/10.1037/pspi0000166

Dupree, C. H., Torrez, B., Obioha, O., \& Fiske, S. (2020). Race-status associations: Distinct effects of three novel measures among White and Black perceivers. Journal of Personality and Social Psychology. https://doi.org/10.31234/osf.io/py3sn

Eason, A. E., Pope, T., Becenti, K. M., \& Fryberg, S. A. (2021). Sanitizing history: National identification, negative stereotypes, and support for eliminating Columbus Day and adopting Indigenous Peoples Day. Cultural Diversity and Ethnic Minority Psychology, 27(1), 1-17. http://dx.doi.org/10.1037/cdp0000345

Eberhardt, J. L., Goff, P. A., Purdie, V. J., \& Davies, P. G. (2004). Seeing Black: race, crime, and visual processing. Journal of Personality and Social Psychology, 87, 876-893. https://doi.org/10.1037/0022-3514.87.6.876

Effron, D. A., Cameron, J. S., \& Monin, B. (2009). Endorsing Obama licenses favoring Whites. Journal of Experimental Social Psychology, 45(3), 590-593. https://doi.org/10.1016/j.jesp.2009.02.001 
Else, H. (2019). How to banish manels and manferences from scientific meetings. Nature, 573, 184-186. https://doi.org/10.1038/d41586-019-02658-6

Emerson, M. O., Smith, C., \& Sikkink, D. (1999). Equal in Christ, but not in the world: White conservative Protestants and explanations of black-white inequality. Social Problems, $46(3), 398-417$.

Epstein, L. M., \& Goff, P. A. (2011). Safety or liberty?: The bogus trade-off of crossdeputization policy. Analyses of Social Issues and Public Policy, 11(1), 314-324. https://doi.org/10.1111/j.1530-2415.2011.01246.x

Fisher, E. L., Deason, G., Borgida, E., \& Oyamot Jr, C. M. (2011). A model of authoritarianism, social norms, and personal values: Implications for Arizona law enforcement and immigration policy. Analyses of Social Issues and Public Policy, 11(1), 285-299. https://doi.org/10.1111/j.1530-2415.2011.01247.x

Fisher v. University of Texas at Austin, No. 11-345 (October 10, 2012).

Foster, S. J. (1999). The struggle for American identity: Treatment of ethnic groups in United States history textbooks. History of Education, 28(3), 251-278. https://doi.org/10.1080/004676099284618

Franklin, A. J. \& Fulani, L. (1974). Cultural content of materials and ethnic group performance in categorized recall. The Empirical Research Conference of Black Psychologists, Ann Arbor, MI, June 1974.

Friedlaender, C. (2018). On microaggressions: Cumulative harm and individual responsibility. Hypatia, 33(1), 5-21. https://doi:10.1111/hypa.12390 
Fryberg, S. A., \& Eason, A. E. (2017). Making the invisible visible: Acts of commission and omission. Current Directions in Psychological Science, 26(6), 554-559. https://doi.org/10.1177/0963721417720959

García-Sánchez, E., Van der Toorn, J., Rodríguez-Bailón, R., \& Willis, G. B. (2019). The vicious cycle of economic inequality: The role of ideology in shaping the relationship between "what is" and "what ought to be" in 41 countries. Social Psychological and Personality Science, 10(8), 991-1001. https://doi.org/10.1177/1948550618811500

Gilbert, K. L., \& Ray, R. (2016). Why police kill Black males with impunity: Applying public health critical race praxis (PHCRP) to address the determinants of policing behaviors and "justifiable" homicides in the USA. Journal of Urban Health: Bulletin of the New York Academy of Medicine, 93 Suppl 1(Suppl 1), 122-140. https://doi.org/10.1007/s11524015-0005-X

Gilliam, W. S., Maupin, A. N., Reyes, C. R., Accavitti, M., \& Shic, F. (2016). Do early educators' implicit biases regarding sex and race relate to behavior expectations and recommendations of preschool expulsions and suspensions. Yale University Child Study Center, 9(28).

Gluszek, A., \& Dovidio, J. F. (2010). The way they speak: A social psychological perspective on the stigma of nonnative accents in communication. Personality and social psychology review, 14(2), 214-237. https://doi.org/10.1177/1088868309359288

Greene, D. W. (2013). A multidimensional analysis of what not to wear in the workplace: Hijabs and natural hair. Florida International University Law Review, 8, 333-362. https://doi.org/10.25148/lawrev.8.2.8 
Greenlee, C. (2019, August 26). How history textbooks reflect America's refusal to reckon with slavery. Vox. https://www.vox.com/identities/2019/8/26/20829771/slavery-textbookshistory

Grother, P., Ngan, M. \& Hanaoka, K. (2019). Face recognition vendor test (FRVT) part 3: Demographic effects (Report No. NISTIR 8280). National Institute of Standards and Technology. https://doi.org/10.6028/NIST.IR.8280

Haidt, J. (2017). The unwisest idea on campus: Commentary on Lilienfeld (2017). Perspectives on Psychological Science, 12(1), 176-177. https://doi.org/10.1177/1745691616667050

Haney-López, I. (2014). Dog whistle politics: How coded racial appeals have reinvented racism and wrecked the middle class. New York: Oxford University Press.

Harwell, D. (2019, December 19). Federal study confirms racial bias of many facial-recognition systems, casts doubt on their expanding use. Washington Post. https://www.washingtonpost.com/technology/2019/12/19/federal-study-confirms-racialbias-many-facial-recognition-systems-casts-doubt-their-expanding-use/

Heitzeg, N. A. (2009). Education or incarceration: Zero tolerance policies and the school to prison pipeline. In Forum on public policy online (Vol. 2009, No. 2). Oxford Round Table. 406 West Florida Avenue, Urbana, IL 61801.

Hetey, R. C., \& Eberhardt, J. L. (2014). Racial disparities in incarceration increase acceptance of punitive policies. Psychological Science, 25(10), 1949-1954. https://doi.org/10.1177/0956797614540307

Hetey, R. C., \& Eberhardt, J. L. (2018). The numbers don’t speak for themselves: Racial disparities and the persistence of inequality in the criminal justice system. Current 
Directions in Psychological Science, 27, 183-187.

https://doi.org/10.1177/0963721418763931

Hooghe, M., \& Dassonneville, R. (2018). Explaining the Trump vote: The effect of racist resentment and anti-immigrant sentiments. Political Science \& Politics, 51(3), 528-534. https://doi.org/10.1017/S1049096518000367

Howard, J. (2009). Concentration camps on the home front: Japanese Americans in the house of Jim Crow. University of Chicago Press.

Howard, S., \& Sommers, S. R. (2015). Exploring the enigmatic link between religion and antiblack attitudes. Social and Personality Psychology Compass, 9(9), 495-510. https://doi.org/10.1111/spc3.12195

Howard, S., \& Sommers, S. R. (2019). White religious iconography increases anti-Black attitudes. Psychology of Religion and Spirituality, 11(4), 382-391. https://doi.org/10.1037/rel0000144

Hughes, J. M., Bigler, R. S., \& Levy, S. R. (2007). Consequences of learning about historical racism among European American and African American children. Child Development, 78(6), 1689-1705. https://doi.org/10.1111/j.1467-8624.2007.01096.x

Hyland, N. E. (2005). Being a good teacher of black students? White teachers and unintentional racism. Curriculum Inquiry, 35(4), 429-459. https://doi.org/10.1111/j.1467873x.2005.00336.x

Isaacs, J. B., Sawhill, I. V., \& Haskins, R. (2008). Getting ahead or losing ground: Economic mobility in America. Brookings Institution. 
Johnston, P. M. G. (2010). Towards culturally appropriate assessment? A contribution to the debates. Higher Education Quarterly, 64(3), 231-245. https://doi.org/10.1111/j.14682273.2010.00463.x

Jones, T., Kalbfeld, J. R., Hancock, R., \& Clark, R. (2019). Testifying while black: An experimental study of court reporter accuracy in transcription of African American English. Language, 95(2), e216-e252. https://doi.org/10.1353/lan.2019.0042

Jraidi, I., \& Frasson, C. (2010, June). Subliminally enhancing self-esteem: Impact on learner performance and affective state. In International Conference on Intelligent Tutoring Systems (pp. 11-20). Springer, Berlin, Heidelberg. http://doi.org/10.1007/978-3-64213437-1_2

Karmali, F., Kawakami, K., Vaccarino, E., Williams, A., Phills, C., \& Friesen, J. P. (2019). I don't see race (or conflict): Strategic descriptions of ambiguous negative intergroup contexts. Journal of Social Issues, 75(4), 1002-1034. https://doi.org/10.1111/josi.12353

Kay, A. C., Gaucher, D., Peach, J. M., Laurin, K., Friesen, J., Zanna, M. P., \& Spencer, S. J. (2009). Inequality, discrimination, and the power of the status quo: Direct evidence for a motivation to see the way things are as the way they should be. Journal of Personality and Social Psychology, 97(3), 21-434. https://doi.org/10.1037/a0015997

Kendi, I. X. (2017). Stamped from the beginning: The definitive history of racist ideas in America. Random House.

Kidder, W. C., \& Rosner, J. (2002). How the SAT creates built-in-headwinds: An educational and legal analysis of disparate impact. Santa Clara Law Review, 43, 131-212. 
Kim, B. L. C. (1973). Asian-Americans: No model minority. Social Work, 18(3), 44-53. https://doi.org/10.1093/sw/18.3.44

King, L. J., \& Brown, K. (2014). Once a year to be Black: Fighting against typical Black History Month pedagogies. Negro Educational Review, 65, 23-43.

Knowles, E. D., \& Lowery, B. S. (2012). Meritocracy, self-concerns, and whites' denial of racial inequity. Self and Identity, 11, 202-222. https://doi.org/10.1080/15298868.2010.542015

Knowles, E. D., Lowery, B. S., Chow, R. M., \& Unzueta, M. M. (2014). Deny, distance, or dismantle? How white Americans manage a privileged identity. Perspectives on Psychological Science, 9(6), 594-609. https://doi.org/10.1177/1745691614554658

Kurtiş, T., Adams, G., \& Yellow Bird, M. (2009). Generosity or genocide? Identity implications of silence in American Thanksgiving commemorations. Memory, 18(2), 208-224. https://doi.org/10.1080/09658210903176478

Kurwa, R. (2019). Building the digitally gated community: The case of Nextdoor. Surveillance \& Society, 17(1/2), 111-117. https://doi.org/10.24908/ss.v17i1/2.12927

Lawton, A. (2000). The meritocracy myth and the illusion of equal employment opportunity. Minnesota Law Review, 85(2), 587-661.

Levy, S. R., West, T. L., Ramirez, L., \& Karafantis, D. M. (2006). The protestant work ethic: A lay theory with dual intergroup implications. Group Processes and Intergroup Relations, 9(1), 95-115. https://doi.org/10.1177/1368430206059874

Lewis, A. E., Chesler, M., \& Forman, T. A. (2000). The impact of "colorblind" ideologies on students of color: Intergroup relations at a predominantly White university. Journal of Negro Education, 74-91. 
Lilienfeld, S. O. (2017). Microaggressions: Strong claims, inadequate evidence. Perspectives on Psychological Science, 12(1), 138-169. https://doi.org/10.1177/1745691616659391

Lindemann, S. (2005). Who speaks “broken English”? US undergraduates’ perceptions of nonnative English. International Journal of Applied Linguistics, 15(2), 188-212. https://doi.org/10.1111/j.1473-4192.2005.00087.x

Livengood, J. S., \& Stodolska, M. (2004). The effects of discrimination and constraints negotiation on leisure behavior of American Muslims in the post-September 11 America. Journal of leisure research, 36(2), 183-208.

https://doi.org/10.1080/00222216.2004.11950019

Luther, K. (2009). Celebration and separation: A troublesome approach to multicultural education. Multicultural Perspectives, 11(4), 211-216. https://doi.org/10.1080/15210960903446036

Maddux, W. W., Galinsky, A. D., Cuddy, A. J., \& Polifroni, M. (2008). When being a model minority is good... and bad: Realistic threat explains negativity toward Asian Americans. Personality and Social Psychology Bulletin, 34(1), 74-89. https://doi.org/10.1177/0146167207309195

Madeira, A. F., Costa-Lopes, R., Dovidio, J. F., Freitas, G., \& Mascarenhas, M. F. (2019). Primes and consequences: A systematic review of meritocracy in intergroup relations. Frontiers in Psychology, 10. https://doi.org/10.3389/fpsyg.2019.02007

Marinari, M. (2005). Racial formation and success among Korean high school students. The Urban Review, 37(5), 375-398. https://doi.org/10.1007/s11256-005-0019-x 
McCabe, J. (2009). Racial and gender microaggressions on a predominantly-White campus: Experiences of Black, Latina/o and White undergraduates. Race, Gender \& Class, 16(1/2), 133-151. http://www.jstor.org/stable/41658864

McCoy, S. K., \& Major, B. (2007). Priming meritocracy and the psychological justification of inequality. Journal of Experimental Social Psychology, 43, 341-351. https://doi.org/10.1016/j.jesp.2006.04.009

McTernan, E. (2017). Microaggressions, equality, and social practices. Journal of Political Philosophy, 26(3), 261-81.

Mekawi, Y., \& Bresin, K. (2015). Is the evidence from racial bias shooting task studies a smoking gun? Results from a meta-analysis. Journal of Experimental Social Psychology, 61, 120-130. https://doi.org/10.1016/j.jesp.2015.08.002

Mendelberg, T. (2001). The race card: Campaign strategy, implicit messages, and the norm of equality. Princeton, NJ: Princeton University Press.

Mercurio, E., \& Filak, V. F. (2010). Roughing the passer: The framing of Black and White quarterbacks prior to the NFL draft. Howard Journal of Communications, 21(1), 56-71. https://doi.org/10.1080/10646170903501328

Miller, R. (1999). Reflecting on racism. Journal of Religious Thought, 55(2/1), 117-121.

Miller, K. S., Potter, G. W., Kappeler, V. E. (2006). The myth of the juvenile superpredator. In Sims, B., Preston, P. (Eds.), Handbook of juvenile justice: Theory and practice (pp. 173192). Boca Raton, FL: CRC.

Mills, C. W. (2007). White ignorance. In S. Sullivan \& N. Tuana (Eds.) Race and epistemologies of ignorance (pp. 13-38). Albany, NY: State University of New York Press. 
Monin, B., \& Miller, D. T. (2001). Moral credentials and the expression of prejudice. Journal of Personality and Social Psychology, 81(1), 33-43. https://doi.org/10.1037/00223514.81.1.33

Morales, M. C., Delgado, D., \& Curry, T. (2018). Variations in citizenship profiling by generational status: Individual and neighborhood characteristics of Latina/os questioned by law enforcement about their legal status. Race and Social Problems, 10(4), 293-305. https://doi.org/https://doi.org/10.1007/s12552-018-9235-3

Morris, W. (2019, August 4). For centuries, black music, forged in bondage, has been the sound of complete artistic freedom. No wonder everybody is always stealing it. The New York Times Magazine: The 1619 Project. https://nytimes.com

Mueller, J. C. (2017). Producing colorblindness: Everyday mechanisms of White ignorance. Social Problems, 64, 219-238. https://doi.org/10.1093/socpro/spw061

Mukherjee, S., Salter, P. S., \& Molina, L. E. (2015). Museum spaces as psychological affordances: representations of immigration history and national identity. Frontiers in psychology, 6, 692. https://doi.org/10.3389/fpsyg.2015.00692

Naturalization Act, 1 Stat $\S 103$ (1790).

Nelson, J. C., Adams, G., \& Salter, P. S. (2013). The Marley hypothesis: Denial of racism reflects ignorance of history. Psychological Science, 24(2), 213-218. https://doi.org/10.1177/0956797612451466

Neville, H. A., Lilly, R. L., Duran, G., Lee, R. M., \& Browne, L. (2000). Construction and initial validation of the Color-Blind Racial Attitudes Scale (CoBRAS). Journal of Counseling Psychology, 47(1), 59-70. https://doi.org/10.1037/0022-0167.47.1.59 
Nier, J. A., Gaertner, S. L., Nier, C. L., \& Dovidio, J. F. (2012). Can racial profiling be avoided under Arizona immigration law? Lessons learned from subtle bias research and antidiscrimination law. Analyses of Social Issues and Public Policy, 12(1), 5-20. https://doi.org/10.1111/j.1530-2415.2011.01248.x

Noe-Bustamante, L., Mora, L., Lopez, M. H. (2020, August 11). About one-in-four U.S. Hispanics have heard of Latinx, but just 3\% use it. Pew Research Center: Hispanic Trends. https://www.pewresearch.org

Obermeyer, Z., Powers, B., Vogeli, C., \& Mullainathan, S. (2019). Dissecting racial bias in an algorithm used to manage the health of populations. Science, 366(6464), 447-453. https://doi.org/10.1126/science.aax2342

O’Connell, H. A. (2020). Monuments outlive history: Confederate monuments, the legacy of slavery, and black-white inequality. Ethnic and Racial Studies, 43(3), 460-478. https://doi.org/10.1080/01419870.2019.1635259

Okonofua, J. A., \& Eberhardt, J. L. (2015). Two strikes: Race and the disciplining of young students. Psychological Science, 26(5), 617-624. https://doi.org/10.1177/0956797615570365

Opie, T. R., \& Phillips, K. W. (2015). Hair penalties: The negative influence of Afrocentric hair on ratings of Black women's dominance and professionalism. Frontiers in Psychology, 6, 1311. https://doi.org/10.3389/fpsyg.2015.01311

Perry, A. M., Rothwell, J., \& Harshbarger, D. (2018, November 27). The devaluation of assets in black neighborhoods: The case of residential property. Brookings. https://www.brookings.edu/research/devaluation-of-assets-in-black-neighborhoods/ 
Perry, S. P., Skinner, A. L., \& Abaied, J. L. (2019a). Bias awareness predicts color conscious racial socialization methods among White parents. Journal of Social Issues, 75(4), 10351056. https://doi.org/10.1111/josi.12348

Perry, S., Skinner, A., Wages, J., \& Parzonka, J. (2019b). Ambivalent reactions to people who deny or admit their gender and racial biases. https://doi.org/10.31234/osf.io/x47q3

Plaut, V. C., Thomas, K. M., Hurd, K., \& Romano, C. A. (2018). Do color blindness and multiculturalism remedy or foster discrimination and racism?. Current Directions in Psychological Science, 27(3), 200-206. https://doi.org/10.1177/0963721418766068

Poplack, S. (2009). How English became African American English. In A. van Kemenade \& B. Los (Eds.) The Handbook of the History of English (pp. 452-476). Oxford: Blackwell.

Quillian, L., \& Pager, D. (2001). Black neighbors, higher crime? The role of racial stereotypes in evaluations of neighborhood crime. The American Journal of Sociology, 107(3), 717-767. https://doi.org/10.1086/338938

Quintanilla, V. D., \& Kaiser, C. R. (2016). The same-actor inference of nondiscrimination: Moral credentialing and the psychological and legal licensing of bias. California Law Review, 104(1), 1-74. https://doi.org/10.15779/Z38CK3H

Raphael, M. J., \& Ungvarsky, E. J. (1993). Excuses, excuses: Neutral explanations under Batson v. Kentucky. University of Michigan Journal of Law Reform, 27(1), 229-275.

Reynolds, J., \& Xian, H. (2014). Perceptions of meritocracy in the land of opportunity. Research in Social Stratification and Mobility, 36, 121-137. https://doi.org/10.1016/j.rssm.2014.03.001 
Rich, M. (2015, April 11). Where are the teachers of color? The New York Times. https://www.nytimes.com/2015/04/12/sunday-review/where-are-the-teachers-ofcolor.html

Richeson, J. A., \& Nussbaum, R. J. (2004). The impact of multiculturalism versus colorblindness on racial bias. Journal of Experimental Social Psychology, 40, 417-423. https://doi.org/10.1016/j.jesp.2003.09.002

Rickford, J. R., \& King, S. (2016). Language and linguistics on trial: Hearing Rachel Jeantel (and other vernacular speakers) in the courtroom and beyond. Language, 92(4), 948-988. https://doi.org/10.1353/lan.2016.0078

Roberts, S. O., Gelman, S. A., \& Ho, A. K. (2017a). So it is, so it shall be: Group regularities license children's prescriptive judgments. Cognitive Science, 41, 576-600. https://doi.org/10.1111/cogs.12443

Roberts, S. O., Guo, C., Ho, A. K., \& Gelman, S. A. (2018). Children's descriptive-toprescriptive tendency replicates (and varies) cross-culturally: Evidence from China. Journal of Experimental Child Psychology, 165, 148-160. https://doi.org/10.1016/j.jecp.2017.03.018

Roberts, S. O., Ho, A. K., \& Gelman, S. A. (2017b). Group presence, category labels, and generic statements influence children to treat descriptive group regularities as prescriptive. Journal of Experimental Child Psychology, 158, 19-31. https://doi.org/10.1016/j.jecp.2016.11.013

Roberts, S. O., \& Rizzo, M. (2020). The psychology of American racism. American Psychologist. https://doi.org/10.31219/osf.io/w2h73 
Roberts, S. O., Weisman, K., Lane, J. D., Williams, A., Camp, N. P., Wang, M., Robison, M., Sanchez, K., \& Griffiths, C. (2020). God as a White man: A psychological barrier to conceptualizing Black people and women as leadership worthy. Journal of Personality and Social Psychology. Advance online publication. https://doi.org/10.1037/pspi0000233

Roy, W. G., \& Dowd, T. J. (2010). What is sociological about music? Annual Review of Sociology, 36, 183-203. https://doi.org/10.1146/annurev.soc.012809.102618

Ruscher, J. B. (2017). Prejudiced communication. Oxford Research Encyclopedia of Communication, (November), 1-21. https://doi.org/10.1093/acrefore/9780190228613.013.419

Salter, P. S., \& Adams, G. (2016). On the intentionality of cultural products: Representations of Black history as psychological affordances. Frontiers in Psychology, 7(August), 1-21. https://doi.org/10.3389/fpsyg.2016.01166

Salter, P. S., Adams, G., \& Perez, M. J. (2018). Racism in the structure of everyday worlds: A cultural-psychological perspective. Current Directions in Psychological Science, 27(3), 150-155. https://doi.org/10.1177/0963721417724239

Sigelman, L., \& Tuch, S. A. (1997). Metastereotypes: Blacks’ perceptions of Whites' stereotypes of Blacks. Public Opinion Quarterly, 61, 87-101. https://doi.org/10.1086/297788

Skinner, A. L., \& Cheadle, J. E. (2016). The "Obama effect”? Priming contemporary racial milestones increases implicit racial bias among Whites. Social Cognition, 34(6), 544558. https://doi.org/10.1521/soco.2016.34.6.544

Skinner, A. L., \& Haas, I. J. (2016). Perceived threat associated with police officers and Black men predicts support for policing policy reform. Frontiers in Psychology, 7(1057). https://doi.org/10.3389/fpsyg.2016.01057 
Skinner, A. L., Meltzoff, A. N., \& Olson, K. R. (2017). “Catching” social bias: Exposure to biased nonverbal signals creates social biases in preschool children. Psychological Science, 28, 216-224. https://doi.org/10.1177/0956797616678930

Skinner, A. L., Olson, K. R., \& Meltzoff, A. N. (2020b). Acquiring group bias: Observing other people's nonverbal signals can create social group biases. Journal of Personality and Social Psychology, 119(4), 824-838. https://doi.org/10.1037/pspi0000218

Skinner, A. L., \& Perry, S. (2020). Are attitudes contagious? Exposure to biased nonverbal signals can create novel social attitudes. Personality and Social Psychology Bulletin, 46, 514-524. https://doi.org/10.1177/0146167219862616

Skinner, A. L., Perry, S. P., \& Gaither, S. E. (2020a). Not quite monoracial: Biracial stereotypes explored. Personality and Social Psychology Bulletin, 46, 377-392. https://doi.org/10.1177/0146167219858344

Smith, P. K., Dijksterhuis, A., \& Chaiken, S. (2008). Subliminal exposure to faces and racial attitudes: Exposure to Whites makes Whites like Blacks less. Journal of Experimental Social Psychology, 44(1), 50-64. https://doi.org/10.1016/j.jesp.2007.01.006

Sommers, S. R., \& Norton, M. I. (2007). Race-based judgments, race-neutral justifications: experimental examination of peremptory use and the Batson challenge procedure. Law and Human Behavior, 31(3), 261-273. https://doi.org/10.1007/s10979-006-9048-6

Southern Poverty Law Center (2019). Whose Heritage? Public Symbols of the Confederacy. Southern Poverty Law Center. https://www.splcenter.org/20190201/whose-heritagepublic-symbols-confederacy

Stephens, N. M., Fryberg, S. A., Markus, H. R., Johnson, C. S., \& Covarrubias, R. (2012). Unseen disadvantage: How American universities' focus on independence undermines 
the academic performance of first-generation college students. Journal of Personality and Social Psychology, 102, 1178-1197. https://doi.org/10.1037/a0027143

Strother, L., Piston, S., \& Ogorzalek, T. (2017). Pride or prejudice?: Racial prejudice, southern heritage, and white support for the Confederate battle flag. Du Bois Review: Social Science Research on Race, 14(1), 295-323. https://doi.org/10.1017/S1742058X17000017

Sue, D. W. (2017). Microaggressions and "evidence": Empirical or experiential reality? Perspectives on Psychological Science, 12(1), 170-172. https://doi.org/10.1177/1745691616664437

Sue, D. W., Capodilupo, C. M., Torino, G. C., Bucceri, J. M., Holder, A. M. B., Nadal, K. L., \& Esquilin, M. (2007). Racial microaggressions in everyday life: Implications for clinical practice. American Psychologist, 62, 271-286. httsp://doi.org/10.1037/0003066X.62.4.271

Thai, M., Hornsey, M. J., \& Barlow, F. K. (2016). Friends with moral credentials: Minority friendships reduce attributions of racism for majority group members who make conceivably racist statements. Social Psychological and Personality Science, 7(3), 272280. https://doi.org/10.1177/1948550615624140

Tukachinsky, R., Mastro, D., \& Yarchi, M. (2015). Documenting portrayals of race/ethnicity on primetime television over a 20 -year span and their association with national-level racial/ethnic attitudes. Journal of Social Issues, 71(1), 17-38. https://doi.org/10.1111/josi.12094

U.S. Census Bureau. (2011). American community survey (ACS). United States Census Bureau. WWw.census.gov/programs-surveys/acs/guidance/comparing-acs-data/2011.html 
van Ryn M, \& Burke J. (2000). The effect of patient race and socio-economic status on physicians' perceptions of patients. Social Science and Medicine, 50(6), 813-828. https://doi.org/10.1016/S0277-9536(99)00338-X

Wallace, S. L., \& Allen, M. D. (2008). Survey of African American portrayal in introductory textbooks in American government/politics: A report of the APSA standing committee on the status of blacks in the profession. Political Science and Politics, 41(1), 153-160.

Weisbuch, M., Pauker, K., \& Ambady, N. (2009). The subtle transmission of race bias via televised nonverbal behavior. Science, 326(December), 1711-1714. https://doi.org/10.1126/science. 1178358

Wetts, R., \& Willer, R. (2019). Who is called by the dog whistle? Experimental evidence that racial resentment and political ideology condition responses to racially encoded messages. Socius: Sociological Research for a Dynamic World, 5, 237802311986626. https://doi.org/10.1177/2378023119866268

White-Lewis, D. K. (2020). The facade of fit in faculty search processes. The Journal of Higher Education, 91(6), 831-857. https://doi.org/10.1080/00221546.2020.1775058

Wilkins, C. L., \& Kaiser, C. R. (2014). Racial progress as threat to the status hierarchy: Implications for perceptions of anti-White bias. Psychological science, 25(2), 439-446. https://doi.org/10.1177/0956797613508412

Willard, G., Isaac, K.-J., \& Carney, D. R. (2015). Some evidence for the nonverbal contagion of racial bias. Organizational Behavior and Human Decision Processes, 128, 96-107. https://doi.org/10.1016/j.obhdp.2015.04.002

Williams, M. T. (2020a). Microaggressions: Clarification, evidence, and impact. Perspectives on Psychological Science, 15(1), 3-26. https://doi.org/10.1177/1745691619827499 
Williams, M. T. (2020b). Psychology cannot afford to ignore the many harms caused by microaggressions. Perspectives on Psychological Science, 15(1), 38-43. https://doi.org/10.1177/1745691619893362

Williams, M. T., Skinta, M. D., Kanter, J. W., Martin-Willett, R., Mier-Chairez, J., Debreaux, M., \& Rosen, D. C. (2020). A qualitative study of microaggressions against African Americans on predominantly White campuses. BMC psychology, 8(111). https://doi.org/10.1186/s40359-020-00472-8

Williams, R. L. (1972). The BITCH-100: A culture-specific test. The American Psychological Association Annual Convention, Honolulu, HI, September 1972. Bethesda, MD: National Institutes of Mental Health.

Williams, R. L. (1997). The ebonics controversy. Journal of Black Psychology, 23(3), 208-214. https://doi.org/10.1177/00957984970233002

Williams, M. J., \& Eberhardt, J. L. (2008). Biological conceptions of race and the motivation to cross racial boundaries. Journal of Personality and Social Psychology, 94, 1033-1047. https://doi.org/10.1037/0022-3514.94.6.1033

Wilson, H. (2014). Turning off the school-to-prison pipeline. Reclaiming Children and Youth, 23(1), 49-53.

Wing, J. Y. (2007). Beyond Black and White: The model minority myth and the invisibility of Asian American students. The Urban Review, 39(4), 455-487. https://doi.org/10.1007/s11256-007-0058-6 
Winifred Kagwa, G. (1976). Utilization of racial content in developing self-awareness. Journal of Education for Social Work, 12(2), 21-27. https://doi.org/10.1080/00220612.1976.10778723

Winston, A. S. (2020a). Scientific racism and North American psychology. Oxford Research Encyclopedia of Psychology, 1-26. https://doi.org/10.1093/acrefore/9780190236557.013.516

Winston, A. S. (2020b). Why mainstream research will not end scientific racism in psychology, 30, 425-430. https://doi.org/10.1177/0959354320925176

Wise, T. (1998). Is sisterhood conditional? White women and the rollback of affirmative action. NWSA Journal, 10(3), 1-26.

Wu, E. D. (2015). The color of success: Asian Americans and the origins of the model minority. Princeton University Press.

Yearwood, G. M. (2018). Heritage as hate: racism and sporting traditions. Leisure Studies, 37(6), 677-691. https://doi.org/10.1080/02614367.2018.1497683

Yogeeswaran, K., \& Dasgupta, N. (2010). Will the "real" American please stand up? The effect of implicit national prototypes on discriminatory behavior and judgments. Personality and Social Psychology Bulletin, 36(10), 1332-1345. https://doi.org/10.1177/0146167210380928

Zheng, R. (2016). Why yellow fever isn't flattering: A case against racial fetishes. Journal of the American Philosophical Association, 2(3), 400-419. 
Zou, L. X., \& Cheryan, S. (2017). Two axes of subordination: A new model of racial position.

Journal of Personality and Social Psychology, 112, 696-717.

https://doi.org/10.1037/pspa0000080 